\title{
The Formation of Optical Membrane Reflector Surfaces Using Uniform Pressure Loading
}

\author{
L. M. Murphy \\ Solar Energy Research Institute \\ C. Tuan \\ University of Nebraska - Lincoln
}

August 1987

Prepared under Task No. 5121.32

FTP No. 651

Solar Energy Research Institute

A Division of Midwest Research Institute

1617 Cole Boulevard

Golden, Colorado 80401-3393

Prepared for the

U.S. Department of Energy

Contract No. DE-AC02-83CH10093 


\section{NOTICE}

This report was prepared as an account of work sponsored by the United States Government. Neither the United States nor the United States Department of Energy, nor any of their employees, nor any of their contractors, subcontractors, or their employees, makes any warranty, expressed or implied, or assumes any legal liability or responsibility for the accuracy, completeness or usefulness of any information, apparatus, product or process disclosed, or represents that its use would not infringe privately owned rights.

\section{Printed in the United States of America \\ Available from: \\ National Technical Information Service \\ U.S. Department of Commerce \\ 5285 Port Royal Road \\ Springfield, VA 22161 \\ - Price: Microfiche A01 \\ Printed Copy A04}

Codes are used for pricing all publications. The code is determined by the number of pages in the publication Information pertaining to the pricing codes can be found in the current issue of the following publications, which are generally available in most libraries: Energy Research Abstracts. (ERA); Government Reports Announcements and Index (GRA and 1): Scientific and Technical Abstract Reports (STARi: and publication. NTIS-PR-360 available from NTIS at the above address. 


\section{PREFACE}

The research and development described in this document was conducted within the U.S. Department of Energy's (DOE) Solar Thermal Technology Program. The goal of this program is to advance the engineering and scientific understanding of solar thermal technology and to establish the technology base from which private industry can develop solar thermal power production options for introduction into the competitive energy market.

Solar thermal technology concentrates the solar flux using tracking mirrors or lenses onto a receiver, where the solar energy is absorbed as heat and converted into electricity or incorporated into products as process heat. The two primary solar thermal technologies, central receivers and distributed receivers, employ various point- and line-focus optics to concentrate sunlight. Current central receiver systems use fields of heliostats (two-axis tracking mirrors) to focus the sun's radiant energy onto a single, towermounted receiver. Point-focus concentrators up to $17 \mathrm{~m}$ in diameter track the sun in two axes and use parabolic dish mirrors or Fresnel lenses to focus radiant energy onto a receiver. Troughs and bowls are line-focus tracking reflectors that concentrate sunlight onto receiver tubes along their focal lines. Concentrating collector modules can be used alone or in a multimodule system. The concentrated radiant energy absorbed by the solar thermal receiver is transported to the conversion process by a circulating working fluid. Receiver temperatures range from $100^{\circ} \mathrm{C}$ in low-temperature troughs to over $1500^{\circ} \mathrm{C}$ in dish and central receiver systems.

The Solar Thermal Technology Program is directing efforts to advance and improve each system concept through solar thermal materials, components, and subsystems research and development and by testing and evaluation. These efforts are carried out with the technical direction of DOE and its network of field laboratories that work with private industry. Together they have established a comprehensive, goal-directed program to improve performance and provide technically proven options for eventual incorporation into the nation's energy supply.

To successfully contribute to an adequate energy supply at reasonable cost, solar thermal energy must be economically competitive with a variety of other energy sources. The Solar Thermal Program has developed components and system-level performance targets as quantitative program goals. These targets are used in planning research and development activities, measuring progress, assessing alternative technology options, and developing optimal components. These targets will be pursued vigorously to ensure a successful program.

This work investigates and documents the results of several aspects of pressure formation of potentially high quality, low cost, and low weight reflector concentrators using high strength structural membranes. In particular, we identify and document the important load/deformation response trends affecting the optical and structural performance of large circular membranes that are uniformly pressure loaded and shaped into nearly parabolic contours. The findings will be useful for both dish and heliostat concentrator applications where the material membrane response can be either elastic or inelastic. This work considers both small and finite deformations in addition to identifying the critical design parameters that are anticipated to have a major impact on the load/ deformation process and hence optical response. 
SEP

TR -3025

We would like to thank Tex Wilkens of DOE for his continued support and encouragement in this work as well as in prior DOE membrane concentrator efforts. In addition, we would like to thank the following individuals for reviewing and commenting on the final draft of this report: Dr. Barry Butler from Science Applications International, Inc.; Dr. Tom Mancini from Sandia National Laboratories, Albuquerque; Dr. Dan Alpert from Candia National Laboratories, Albuquerque; Mr. David White from Solar Kinetics, Inc.; and the numerous SERI staff members who commented on the various drafts.

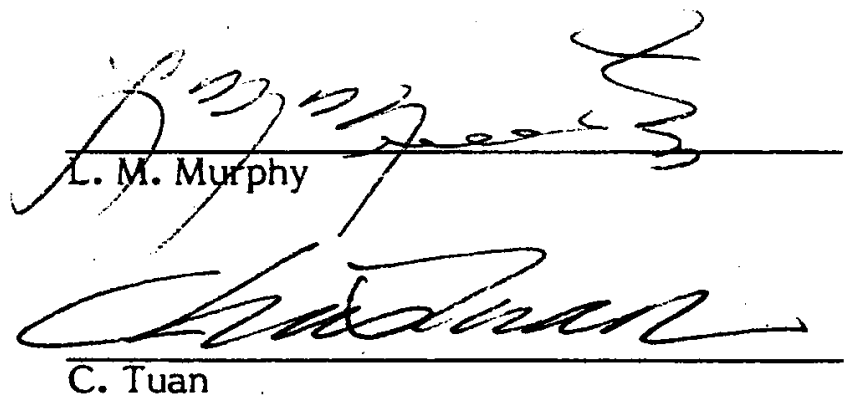

Approved for

SOLAR ENERGY RESEARCHHSTITUTE

Goral C. Graf, Director

Solar Heat Research Division

iv 


\section{SUMMARY}

\section{Objectives}

The objectives of this work are to define the structural/optical membrane response issues associated with uniform pressure loading of initially flat membrane surfaces into nearly parabolic surfaces. Large deformations and the resulting reflector shapes that are needed for parabolic dish concentrator applications and that are accompanied by inelastic material response are of particular interest. Further, we wish to identify the various structural/material phenomena that make the resulting surface contours nonparabolic and to quantify the impact of these effects as much possible.

\section{Discussion}

Stretched membranes for concentrating solar collectors offer the prospect of being very lightweight, structurally efficient, potentially low cost, and potentially similar in optical performance compared to the more conventional rigid glass/metal concentrator design approaches used in current heliostat and parabolic dish applications. In this work, we concentrate on the membrane contour or shape, which is of primary importance to the optical performance of the concentrator. In particular, we investigate the structural and optical membrane response issues and the class of membrane shapes that result from the membrane-formation process. In addition, we examine the deviations from the desired parabola resulting from uniform pressure loading of circular, axisymmetric, and initially flat membrane surfaces having uniform thickness. Such a pressure-loading, shapeforming procedure has been used to develop prototypes of stretched-membrane reflector modules for both parabolic dish and heliostat applications. The parabola is the basis of comparison since it is the most desired contour for both focusing heliostats and parabolic dishes, and the degree to which the parabola is approximated will determine the collector performance. We also discuss the limitations and the optical-quality implications of using this approach to form the membrane reflector surface. Though the results of this study are applicable to both membrane heliostats and dishes, the major emphasis of this work is on dish applications.

Unfortunately, as described in more detail later, homogeneous and axisymmetric membranes that are uniformly pressure loaded will in general assume a surface shape that is not parabolic. In fact, for most cases, the limiting shape will be spherical rather than parabolic. This is because, as can be shown for a uniformly pressure-loaded membrane, with constant thickness and with uniform tension in the membrane (both spatially and in direction), the resulting membrane surface is spherical based on equilibrium considerations alone. This is true whether the membrane material response is elastic or inelastic. Note, however, that in some situations, the sphere can provide a quite adequate approximation to the parabola.

The following three primary issues are addressed in this report to assess the adequacy of pressure-forming optical reflector surfaces: (1) the adequacy with which a spherical surface can approximate the ideal parabola, (2) shape distortion relative to parabolic and spherical contours caused by elastic material response, and (3) membrane surface shapes resulting from inelastic material response. A quantified description of the structural/ surface contour response of the optical membrane surface is provided to aid in the design of stretched-membrane concentrators. Since the emphasis of this investigation is on dish applications, the most extensive descriptions and discussions are presented for the large deformation analyses in which inelastic material response is dominant. 
TR-3025

\section{Conclusion}

We have studied the shape-distortion effects relative to the desired parabolic reflector shape associated with uniform pressure forming of initially flat, circular membranes supported only at the edges, and have related these surface-distortion effects primarily to variations in focal length over the membrane surface. Based on the analysis results obtained, and the assumptions defined in more detail in the report, we have reached the following major conclusions:

- Pressure-loaded membranes tend to be spherical in shape, which sometimes can closely approximate an ideal parabolic surface. A close approximation for larger $\mathbf{f}_{o} / \mathrm{D}^{\prime} \mathrm{s}^{*}$ is the sphere, but for very small $f_{o} / D$ 's this approximation becomes increasingly poor. Elastic membranes are always flatter in the center region and more sloped near the outer radius than the perfect sphere that has the same curvature at the membrane center. In addition, the spherical shape, which is approached with plastic deformation, always has more curvature (i.e., lower radius of curvature and shorter focal length) at the outer radius than does the nominal perfect sphere. Thus, it appears that the sphere is the best approximation we might approach with the elastic/plastic forming of the metal membranes that are uniformly pressure loaded.

- When the membrane responds elastically, the degree to which the final shape approximates a spherical surface depends on both $\mathrm{f}_{\mathrm{o}} / \mathrm{D}$ and the dimensionless stiffness parameter (Modulus $x$ membrane thickness/initial tension $=E t / T_{0}$ ). Shapes that are nearly spherical and that approximate the ideal parabola quite closely can be attained with totally elastic membrane systems if $f_{o} / D>2.0$ and if $E t / T_{0}$ is small. When $E t / T_{0}$ is large, then nonuniform tension states in the membrane can cause unacceptable distortions. Further, if $E t / T_{0}$ is large, the required $f_{o} / D$ for acceptable surface contours may grow appreciably above 2.0 to limit the distortions caused by elastic material response. Further, if $f_{0} / D<2.0$ even when $E t / T_{0}$ is small, the disagreement between the sphere and parabola can be a concern from an optical performance perspective.

- Figure S-1 shows findings with respect to pressure forming an initially flat membrane to a specific $f_{o} / D$ and facet size. Here we see that, for optical elements having $\mathrm{f}_{\mathrm{o}} / \mathrm{D}>10$ that are typical of heliostat designs, elastic designs resulting in good parabolic surfaces appear to be feasible. Also for $\mathrm{f}_{0} / \mathrm{D}^{\prime} \mathrm{s}<10$, elastic distortions start to become a concern with many metal membrane designs, but good elastic contours using polymer membranes may be possible for $f_{0} / D$ values somewhat below 3.5. Further, inelastic designs are required for steel, aluminum, and many polymer designs for $\mathrm{f}_{\mathrm{o}} / \mathrm{D}$ values below approximately 3.5, 2.0, and 1.0, respectively. Moreover, for optical elements with $f_{0} / D<2.0$, the number of small-diameter optical facets required to approximate a large area, single-facet dish with $f_{0} / D=0.6$ is small and decreases with decreasing $f_{o} / D$. Conversely, for reflector elements with $f_{o} / D>2.0$, the facet size decreases and the number of facets required to produce a given concentrator area increases. Finally, for nominal $\mathrm{f}_{\mathrm{o}} / \mathrm{D}$ 's $<1.5$, focal length variations relative to the parabolic shape becomę quite noticeable.

- Inelastic material response can lead to significantly smaller deviations from a perfect sphere than will elastic material response. This is because the plastic deformations

* $F_{0}$ is the focal length at the dish center and is sometimes referred to as the nominal focal length. $D$ is the dish diameter. 


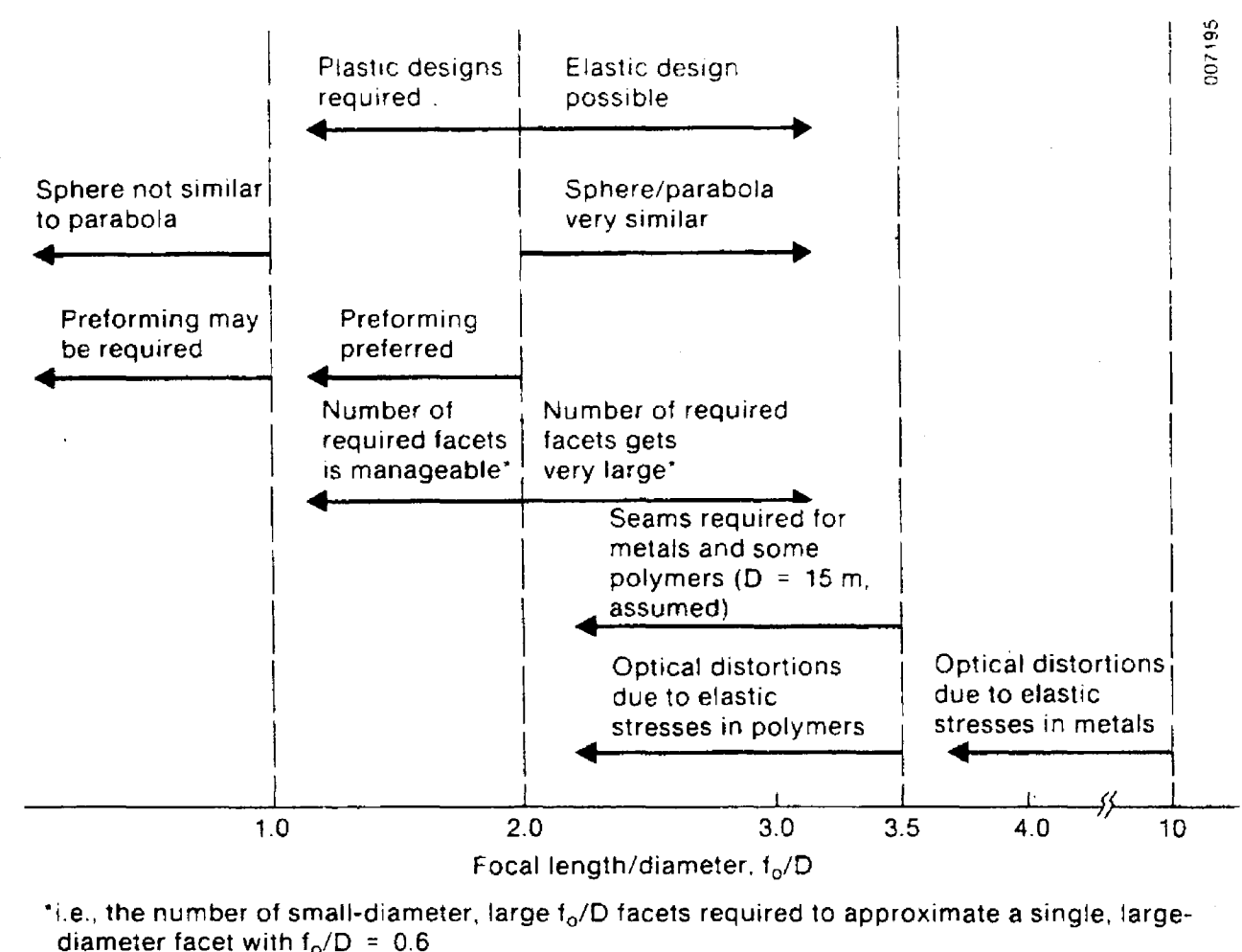

Figure S-1. Surface Shaping and Response Phenomena as a Function of $\mathrm{f}_{\mathrm{o}} / \mathrm{D}$ for Pressure-Formed Membranes

will tend to relieve stress nonuniformities caused by elastic deformations and will thus make the stress distribution over the membrane surface more uniform; hence the membrane will become more spherical.

- The effect of work hardening on surface contour, which was considered in this study, did not appear to have a large deleterious impact on the surface contour, although for the cases studied, non-work-hardening material response always led to somewhat better focal-length uniformity. The major negative impact of work hardening appears to be due to the somewhat greater stress nonuniformity at the edge of the membrane when work hardening is present.

- A reduction of the forming pressure on a membrane that has undergone large plastic deformations results in worsening of the focal-length nonuniformity in the membrane center region with some increase in focal-length uniformity at the edge. It is possible, because of the area effect at large radii, that the overall optical performance may be improved. A more complete optical analysis is needed to verify this.

This report does not address the distortion effects caused by membrane seams, thickness nonuniformities, material anisotropy, and spatial modulus variations nor does it address those distortions caused by support frame displacements, rotations, and nonuniform and nonaxisymmetric pressures. Hence these additional problems, when combined with the deleterious effects studied here, suggest that preforming of the membrane against a mandrel would be quite beneficial, especially if high-performance facets with $\mathrm{f}_{0} / D<1$ 
are required. However it is too early to rule out the potentially inexpensive pressureforming technique. This is especially true if larger $f_{0} / D$ facets, or if facets with lessstringent* optical-quality requirements, are desired. Further, the potential benefits of nonuniform but axisymmetric forming loads may prove to be attractive. It is recommended that we carry out more detailed optical analyses of the shape-distortion effects defined in this work. This will help us ensure that the effects already identified will not prevent this forming approach from being applied to realistic designs.

* For example, such lower optical-quality facets may yield acceptable performance when combined with secondary concentrators. 


\section{TABLE OF CONTENTS}

1.0 Introduction $\ldots \ldots \ldots \ldots \ldots \ldots \ldots \ldots \ldots \ldots \ldots \ldots \ldots \ldots \ldots \ldots \ldots, 1$

2.0 Spherical Surface Approximation to a Parabolic Surface $\ldots \ldots \ldots \ldots \ldots \ldots . . . .3$

3.0 Shape Distortions Caused by Elastic Material Response $\ldots \ldots \ldots \ldots \ldots \ldots$. 8

4.0 Membrane Surface Shapes Considering Inelastic Material Response ........ 14

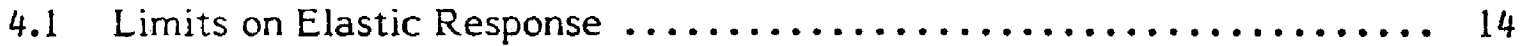

4.2 Large Deformations Accompanied by Inelastic Material Response under Increasing Loads ............................. 16

4.3 Deformation Response Caused by Subsequent Pressure Reduction ...... 26

5.0 Conclusions and Recommendations $\ldots \ldots \ldots \ldots \ldots \ldots \ldots \ldots \ldots \ldots \ldots . \ldots \ldots$

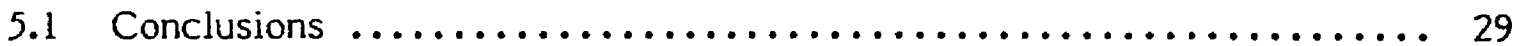

5.2 Recommendations for Further Work $\ldots \ldots \ldots \ldots \ldots \ldots \ldots \ldots \ldots \ldots, 30$

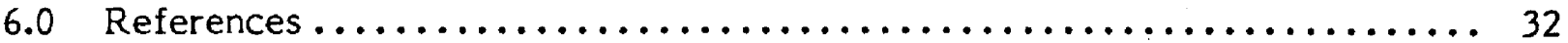

Appendix A Membrane Focal Length and Curvature Change Corresponding to Finite Deformation $\ldots \ldots \ldots \ldots \ldots \ldots \ldots \ldots \ldots \ldots \ldots \ldots \ldots \ldots \ldots \ldots, 35$

Appendix B Strain Limitations Impacts on Converged Load/Deformation Solutions $\ldots \ldots \ldots \ldots \ldots \ldots \ldots \ldots \ldots \ldots \ldots \ldots \ldots \ldots \ldots, 38$ 


\section{LIST OF TABLES}

$\underline{\text { Page }}$

3-1 Geometry and Material Properties of Elastic Membranes...$\ldots \ldots \ldots \ldots \ldots \ldots 11$

4-1 Geometric and Material Property/Response Assumptions Used in the Inelastic Analyses $. \ldots \ldots \ldots \ldots \ldots \ldots \ldots \ldots \ldots \ldots \ldots \ldots \ldots \ldots, 17$ 


\subsection{INTRODUCTION}

Stretched membranes for concentrating solar collectors offer the prospect of being very lightweight, structurally efficient, potentially low cost, and potentially similar in optical performance compared to the more conventional rigid glass/metal concentrator design approaches used in current heliostat and parabolic dish applications. Since details of the relative benefits offered by stretched membranes are given elsewhere, we will focus on other issues that are essential to realizing the full benefits of stretched-membrane reflectors. In particular, in this work we will concentrate on the membrane contour or shape that is attained by pressure loading the surface. The membrane contour is of primary importance to the optical performance of the concentrator. For optical reflector concentrator applications, the parabola is the most desired contour for both focusing heliostats and parabolic dishes, and the degree to which the parabolic contour is approximated will determine the collector performance. In this report, we investigate the structural/optical membrane response issues and the class of membrane shapes resulting from pressure forming. Such a pressure-loaded, shape-forming procedure has been used in the development of stretched-membrane prototype reflector modules for both parabolic dish [1-7] and heliostat [8-11] applications. We will examine the deviations from the desired parabolic shape resulting from uniform pressure loading of circular, axisymmetric, and initially flat membrane surfaces having uniform thickness. We will also discuss the limitations and the optical quality implications of using this approach to form the membrane reflector surface. Though the results of this study will be applicable to membrane heliostats and dishes, the major emphasis of this work is on dish applications.

Unfortunately, as described in more detail later, homogeneous and axisymmetric membranes that are uniformly pressure loaded will in general assume a surface shape that is not parabolic. In fact, for most cases, the limiting shape will approach a spherical rather than a parabolic contour. This is because, as can be shown quite clearly in Refs. 12-14, for a uniformly pressure-loaded membrane with constant thickness and uniform tension in the membrane (both spatially and in direction), the resulting membrane surface is spherical based on equilibrium considerations alone.

Further, it is easily shown that if the tension state in the membrane is nonuniform, a nonspherical membrane shape can be expected. This is true whether the membrane material response is elastic or inelastic. Note, however, that in some situations, the sphere can adequately approximate the parabola; the situations that can lead to membrane shapes that are quite close to the desired parabolic shape must be more fully understood.

Nonuniform tensions in uniformly pressure-loaded membranes result from nonuniform straining when a flat sheet is formed into a doubly curved surface such as that approaching a sphere; thus geometric compatibility constraints require that nonuniform strains will exist. Hence, if the material is elastic, nonuniform stresses caused by the nonuniform deformation and straining will also exist. Further, even when the membrane material responds in an inelastic manner, some stress nonuniformity can be anticipated. For example, in the case of initially flat, circular membranes, the circumferential constraints at the edge lead to the largest nonuniformity in the strain distribution near the rim of the membrane when the membrane is deformed under the pressure load.

In prior work [8], which studied the response of membranes that exhibited elastic material response, we found that a uniform tension state in the membrane is approached only if either the nominal focal length/dish diameter $(\mathrm{f} / \mathrm{D})$ attained was large, or if the quantity $E t / T_{0}$ was sufficiently small; then the desired optical shape was attained. Here, 
$E$ is the Young's modulus of the material, $t$ is the thickness of the membrane, and $T_{0}$ is the initial tension in the membrane. The numerator in this factor (Et) represents the effective mechanical stiffness of the membrane while $T$ gives a measure of the geometric-induced stiffness based on the initial tension. Thus, if the membrane is quite compliant (i.e., Et is small), it can assume its deformed shape with little increase or variation in the stress field due to that deformation; then the spherical shape is approached. Further, if the initial membrane tension is large, then the average stress increments in the membrane attributable to moderate deformations can be relatively small compared to the initial uniform tension, and again the overall tension state will remain nearly uniform and the spherical shape will be approached.*

If we consider pressure-forming cases where large finite deformations are required, such as for dish applications and when the membrane material exhibits inelastic material response under the applied load, it would also seem possible to attain a spherical shape. This would most likely occur if the material yields and has a very uniform and low plastic modulus as suggested in Refs. 1, 2, and 3. Then the stresses in the membrane material that has yielded will be nearly uniform and, for a membrane of uniform thickness, the resulting pressure-loaded shape again will approach a spherical contour.

Thus the following three major issues must be addressed in more detail to assess the adequacy of pressure-forming optical reflector surfaces: (1) the adequacy with which a spherical surface can approximate the ideal parabola, (2) shape distortions relative to parabolic and spherical contours caused by elastic material response, and (3) membrane surface shapes resulting from inelastic material response. These three issues will be addressed in the above order, and we will provide a quantified description of the structural/surface contour response of the optical membrane surface to aid in the design of stretched-membrane concentrators. Since the emphasis of this investigation is on dish applications, the most extensive descriptions and discussions will be presented for the large deformation analyses in which inelastic material response is dominant.

* Actually for the cases studied in Ref. 8, ( $\left.f_{0} / D>2.0\right)$ the ideal parabolic shape can be approximated quite well with a perfect spherical shape. 


\subsection{SPHERICAL SURFACE APPROXIMATION TO A PARABOLIC SURFACE}

We now address the question of how closely a perfect sphere approaches the ideal parabola. Figures 2-1 through 2-3 illustrate a few relative comparisons of perfect parabolas and spheres in terms of common surface shape parameters used in the structural shell and concentrator analysis disciplines. Because the comparison assumes perfect shapes, and because no detailed optical performance analysis has been carried out, these relative comparisons should only be used to indicate where potential problems may exist and not as quantified estimates or indicators of likely optical performance of the respective concentrator types.

Focal length is a commonly used parameter to describe concentrating and, in particular, imaging parabolic solar reflectors for a wide range of design parameters and applications. In subsequent discussions, we will denote the focal length at the concentrator vertex by $f_{0}$ whether the concentrator is parabolic or not. For a perfect parabolic reflector revolved about its axis, any incoming light rays that are parallel to the axis of the collector will be redirected to, and focused at, the focal point $\mathrm{P}$ as shown in Figure 2-la; thus the parabolic reflector is characterized by a single focal length, which we will call $\mathrm{f}_{\mathrm{o}}$ as indicated in Figure $2-1 \mathrm{a}$. The situation with a perfectly spherical reflector is not so simple and cannot be characterized by either a single focal length or single focal point. Rather, for a perfect spherical surface, the light rays that are parallel to the axis of revolution will be reflected to different points along the axis of the collector. Figure $2-1 b$ shows the geometry considered in these preliminary analyses. $\phi_{0}$ and $\phi_{e}$ correspond to the rim angle using the ideal focal point $\left(f_{o}\right)$ and the actual focal point corresponding to the edge of the collector $\left(f_{e}\right)$, respectively, as described in Figure 2-lb. We also assumed that the vertex of the spherical surface has the same position and focal length as the parabolic surface of interest. The rim angle of the collector is the angle formed between the axis of the collector and the line connecting the focal point to a point on the collector rim. We will use this focal-length variation of ten in subsequent sections to indicate the deviation from a parabola, which is characterized by a single focal length, as noted earlier.

In Figure 2-2 we show the deviation in focal length between a geometrically perfect sphere and a geometrically perfect parabolic surface, each having the same aperture area as described in Figure 2-1. Here, the ratio of the focal length (corresponding to the edge of the dish) to that of the center $\left(\mathrm{f}_{\mathrm{e}} / \mathrm{f}_{\mathrm{o}}\right)$ is shown as a function of the ratio $\mathrm{f}_{\mathrm{o}} / \mathrm{D}$. When using Figure 2-2, remember that a perfect parabola has a constant focal length $f_{0}$. On the right ordinate, we show the value of either $\phi_{o}$ or $\phi_{e}$, both as described in Figure 2-1. In this plot, we see that there is virtually no difference between the perfect parabola and the sphere approximation above an $f_{0} / D$ of 2.0 . However, as the value of $\mathrm{f}_{\mathrm{g}} / \mathrm{D}$ falls below 2, and in particular below about 0.6 , the deviation of the sphere from the parabola is quite dramatic. Indeed, for the spherical surface with an $f_{0} / D$ of 0.288 , which corresponds to a $\phi_{0}$ of $90^{\circ}$, $\phi_{e}$ has a value of $120^{\circ}$, and rays reflected from the edge of the reflector are directed to the apex of the spherical surface. As a comparison, note in this figure that at $f_{O} / D$ values of about $0.6,1.0$, and 2.0 , the corresponding deviations of the spherical surface from the parabolic surface in terms of $\mathrm{f}_{\mathrm{e}} / \mathrm{f}_{\mathrm{o}}$ are about $0.90,0.967$, and 0.992 , respectively.

Finally, in Figure 2-2 we also indicate on the ordinate the corresponding nominal $\mathrm{f}_{\mathrm{o}} / \mathrm{D}$ values for various current prototype parabolic dish and heliostat module designs. The test-bed concentrator (TBC) $[15,16]$ with an $f_{d} / D$ of 0.6 , corresponds to a highperformance state-of-the-art glass/metal parabolic concentrator developed under DOE's guidance; it is not a stretched-membrane concentrator. The TBC $[15,16]$ is typical of 


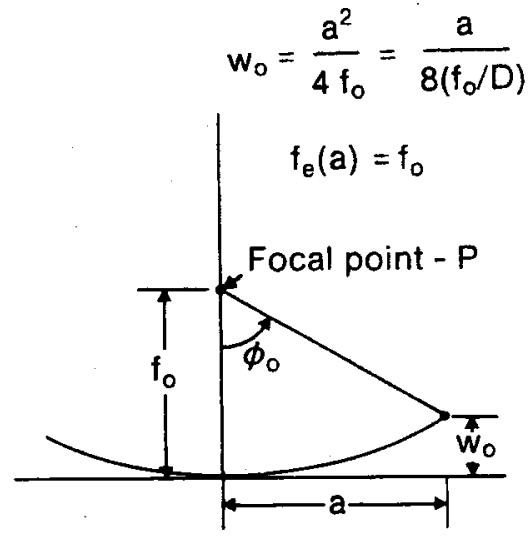

(a) Ideal parabolic geometry

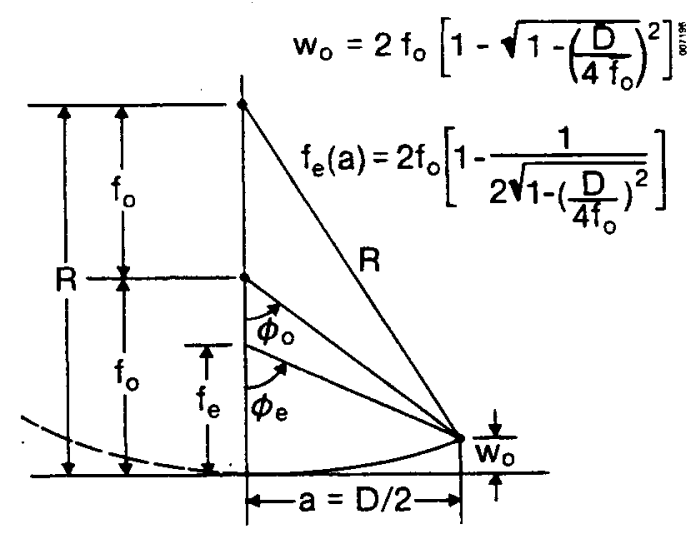

(b) Ideal spherical geometry

Figure 2-1. A Comparison of Ideal Spherical and Parabolic Geometries and the Geometric/Optical Parameters Describing Each of These Surfaces

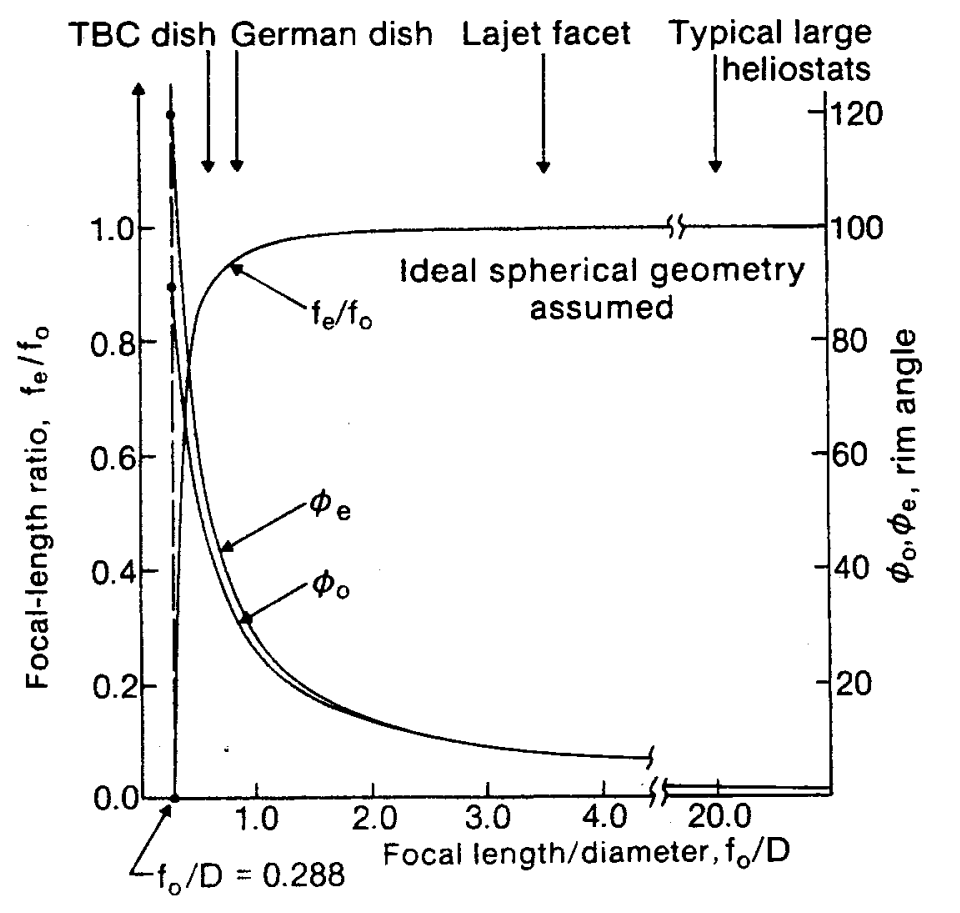

Figure 2-2. Membrane-Edge Focal Length $\left(f_{e}\right)$ Divided by Center Focal Length ( $f_{o}$ ) of the Sphere as a Function of $f_{o} / D$, and Rim Angles $\phi$, and $\phi_{e}$ as a Function of $\mathrm{f}_{\mathrm{o}} / \mathrm{D}$ 


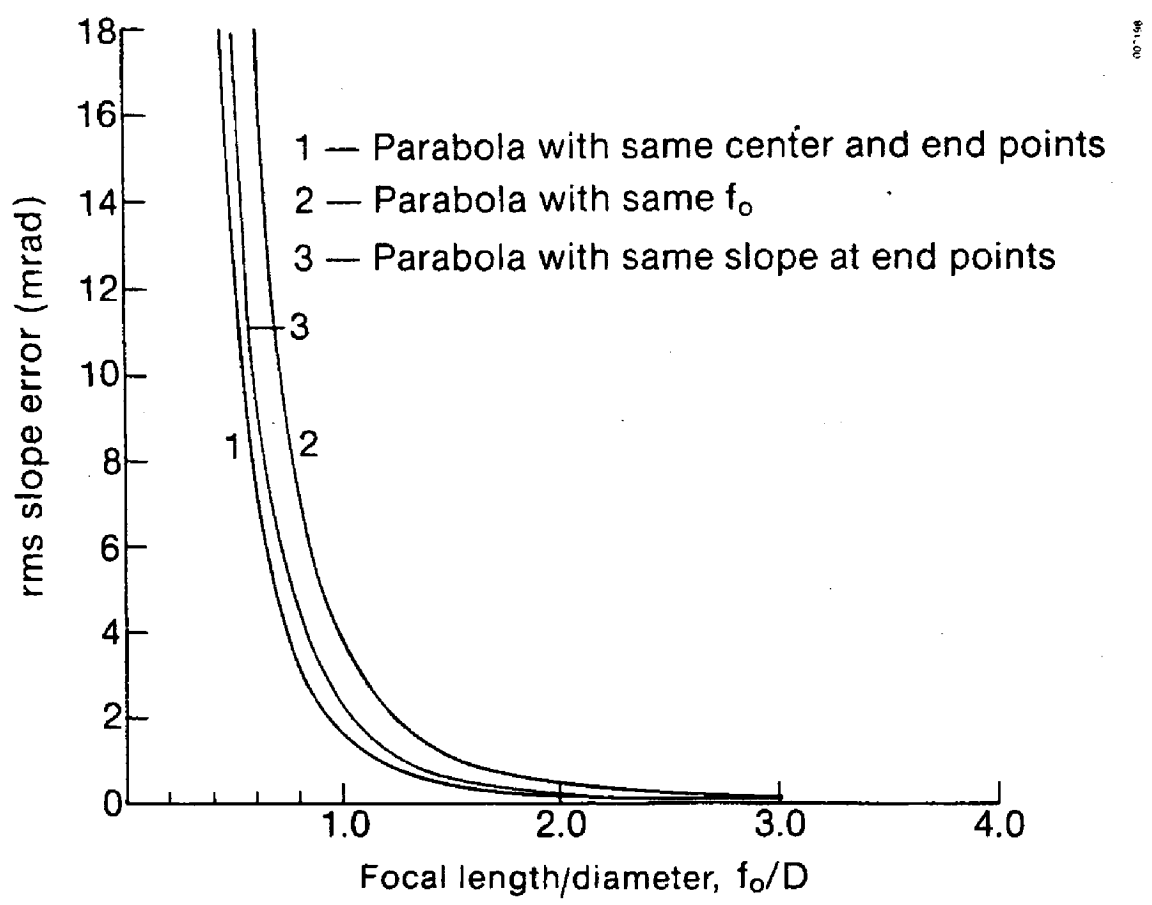

Figure 2-3. rms Slope Deviation for an Ideal Spherical Surface as Measured Relative to a Perfect Parabolic Surface for Three Different Surface Fits

numerous current glass/metal concepts with which stretched-membrane concepts must compete in terms of cost and performance. The German dish, with an $\mathrm{f}_{\mathrm{o}} / \mathrm{D} \sim 0.8$, corresponds to the first-generation German/Saudi stretched-membrane prototype parabolic dish design that was designed and fabricated to demonstrate the concept's feasibility $[1,2,3]$. Thus we can see that the range of $f_{0} / D$ 's from 0.6 to 1.0 is appropriate for largefacet dish applications. The LaJet [6] concentrator uses many small-diameter stretchedmembrane facet elements, each with an $\mathrm{f}_{\mathrm{o}} / \mathrm{D}$ of 3.5 as indicated in Figure 2-2. The "typical large heliostat" in Figure 2-2 is representative of many current large glass/metal heliostats $[17,18]$ as well as the large stretched-membrane concepts that are currently being developed by Sandia National Laboratories [10,11]. Figure 2-2 shows that typical large-facet dishes will not only have $f_{0} / D$ 's in the range 0.6 to 1.0 , but that this also corresponds to an $f_{0} / D$ range in which significant differences between the spherical and parabolic shapes start to emerge.

In Figures 2-1 and 2-2, we assumed one particular "fit" to the parabolic surface (i.e., we assumed that the sphere and the parabola had the same position and curvature at the vertex). Other fits are possible that may provide a better match between the two surfaces for optical performance. We can investigate other fits using an rms surface error approach that is often used to assess concentrators in which the slope deviations corresponding to a perfect parabola as compared to a sphere (or any specific contour of interest) are expressed in terms of a surface averaged rms slope error or deviation. The slope deviation approach can be used to accurately indicate the optical performance of a given concentrator only when used with a baseline optical analysis if the errors 
(deviations from the perfect parabola) are randomly distributed and small. When the deviations are neither random nor small (such as when considering systematic deviations in a sphere as measured relative to a perfect parabola), such an approach cannot in general be used to accurately quantify changes in optical performance. This rms slope error approach can, however, be used to indicate trends in the deviations between specific surfaces and to give a qualitative indication of when two surfaces have significantly different profiles. We use the rms slope error measure in Figure 2-3 to show the effects of using different approaches to fitting the sphere to the parabola. Each of these fits corresponds to a different way that a sphere, having the same aperture as the parabola, can be configured to approximate the parabolic surface. In the first case, shown in Figure 2-3, the parabola is assumed to have the same vertex position and curvature at the vertex as the sphere. (This is the same situation as described in Figure 2-1). In the second case, the sphere and the parabola are assumed to have coincident edge and vertex positions. Finally, in the third case, the spherical and parabolic surfaces are assumed to have the same slope and position of the rim edge. We see that each of these measures gives qualitatively similar results over the whole range of $f_{o} / D$ 's regardless of the fit procedure used. Further, Figure 2-3 shows that none of the three spherical surfaces closely approximates the parabolic shape when $f / D$ is small but all are adequate when $f_{0} / D$ is large $(>3.0)$. Clearly this whole issue of the preferred approach for attaining the best fit must be coupled with an optical analysis to fully resolve this problem. Such analyses are currently being carried out at SERI.

One can avoid the primary problem of differences between spherical and parabolic surfaces associated with short focal lengths since it is possible to approximate a single large-area parabolic dish facet having a small $\mathrm{f}_{0} / \mathrm{D}$ with a number of smaller area facets, each with relatively much larger facet $f / D$ 's. ${ }^{*}$ This is similar to the concept of multiple small-area facets developed by LaJet [6]. This question arises when designers wish to avoid primarily the manufacturing problems associated with large-diameter facets that have a small $f_{\rho} / D$ and also the associated spherical aberration problem. In Figure 2-4, we illustrate the approximate number of small-area facets required to make an equivalent large-area dish having a small $f_{o} / D$ as a function of small-area-facet $f_{0} / D$. We have done this for two baseline equivalent large-area facets with $\mathrm{f}_{\mathrm{o}} / \mathrm{D}$ 's of 0.6 and 1.0 , respectively. Here we see that many facets are required to approximate a larger area, small- $f_{o} / D$ dish consisting of small facets that have much larger $f_{o} / D$ 's. Furthermore, we see that the number of required modules can drop significantly if the $f_{0} / D$ of the nominal larger area dish is increased; consider the drop in the number of required smallarea facets by decreasing the $f_{o} / D$ of the nominal large-area facet from 0.6 to 1.0 as shown in the Figure 2-4.

* We will not go into detail here since it is beyond the scope of this work, but we have compared only axisymmetric parabolic and spherical contours having the same axis of symmetry. Additional optical and shape-matching difficulties will occur when we try to match a local nonaxisymmetric portion of a parabolic shape (e.g., at the edge of the parabola) with a corresponding local spherical shape. 


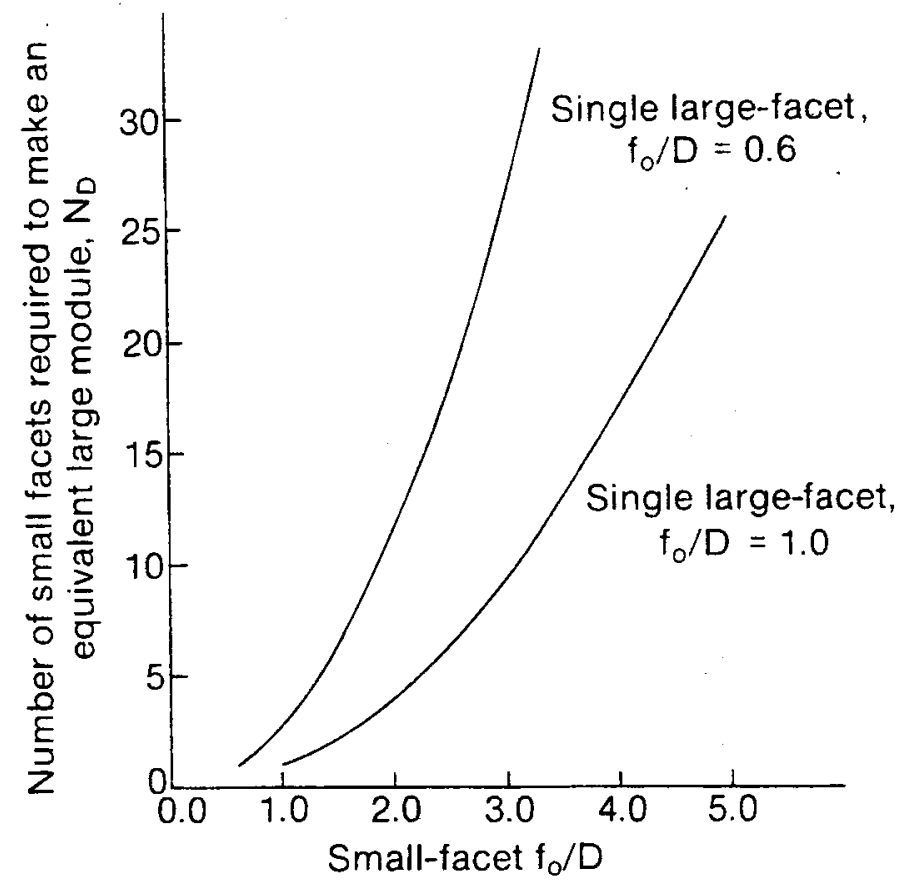

Figure 2-4. Number of Facets Required in a Multifacet Dish as a Function of Small-Facet $\mathrm{f}_{\mathrm{o}} / \mathrm{D}$ for Two Baseline, Large-Facet $\mathrm{f}_{\mathrm{o}} / \mathrm{D}$ Dish Values 
TR-3025

\subsection{SHAPE DISTORTIONS CAUSED BY ELASTIC MATERIAL RESPONSE}

In addressing the membrane deformations corresponding to elastic material response, we can use the information developed in Ref. 8 to describe the deformation processes of the membranes that are subjected to axisymmetric, uniform pressure loading and with varjous levels of pretension. Other assumptions used in Ref. 8, and which are used here, are initially flat shapes before pressure loading, uniform membrane thickness, linear elastic material response, and a nonlinear strain/deformation relationship. Also, our discussion here will focus on assumed rigid-boundary conditions, although we do discuss nonrigid membrane attachments in Ref. 8. Further, note that we considered and correlated our analysis predictions for nominal $f_{o} / D$ 's from about 12.0 down to 3.5 in Ref. 8. As noted earlier, $f_{o} / D=12.0$ is typical of very short focal-length heliostats, while $f_{o} / D=3.5$ is typical of the small-facet dish concept developed by LaJet [18].

In Figure 3-1, we show the geometry for a typical stretched-membrane heliostat or dish reflector module. Here the focal length is denoted by $f$, the local radius by $r$, the total radius of the membrane (which is assumed to be attached to a rigid toroidal support frame) by $a$, the uniform pressure applied normal to the membrane by $P$, and the radial membrane displacement by $u$. In Figures 3-2 through 3-5, we show the nondimensionalized deformation ( $w / a)$ versus normalized radial position $(r / a)$, the slope versus normalized radial position, the normalized focal length ( $f / f_{o}$ ) versus normalized radial position, and the normalized membrane tensions $\left(T_{r} / T_{0}\right.$ and $\left.T_{\theta}^{O} / T_{0}\right)$ as a function of radial position, respectively. $T_{o}, T_{r}$, and $T_{\theta}$ represent the initial, local radial, and local circumferential membrane tensions, respectively. $\mathrm{f}_{0}$ and $\mathrm{w}_{8}$ correspond to the membrane focal length and displacement at the membrane center, $r=8$.

In Figures 3-2 through 3-5, we plotted results for two specific membrane designs selected from those studied in Ref. 8. One membrane design is of steel construction (Case 1) with a nominal $\mathrm{f}_{\mathrm{o}} / \mathrm{D}$ of 12.2 , whereas the other membrane design (Case 2 ) corresponds to a polymer membrane with a nominal, fairly short focal length (nominal $f_{o} / D$ of 3.5 ). The material properties and geometry of the short focal-length polymer membrane and longer focal-length metal membrane are listed in Table 3-1. Figure 3-2 (normalized displacement versus normalized radial position) shows that based on simple visual inspection of the relative surface deformations, there is good agreement between the predicted elastic solution and an ideal parabolic solution for these two cases. However, in Figure 3-3, we see more clearly the development of deviations in slope from the desired slope corresponding to the parabola. Note that, from an optical performance perspective, differences in slope will affect the ability to accurately focus the reflected energy at the desired focal point quite heavily; this is because surface slope determines the direction in which reflected rays are directed. Furthermore, in Figure 3-4, we see the impact on optical focusing performance more clearly by investigating the focal-length changes as a function of the radial position for the two cases considered. Note that the long focallength case in this comparison has a relatively much greater focal-length change than does the short focal-length case* because the effective membrane stiffness of the short focal-length design is extremely low compared with the effective membrane stiffness of

* These examples were chosen to demonstrate the important structural/optical response phenomena. A more detailed optical analysis is needed to define the impact on total concentrator performance since a given fractional focal-length change will have varying effects as a function of nominal $\mathrm{f}_{\mathrm{o}} / \mathrm{D}$ (e.g., a $10 \%$ change in focal length is not a significant issue with large $\mathrm{f}_{0} / \mathrm{D}$ heliostats but it can have significant impact on the performance of short $f_{O} / D$ dish concentrators). 


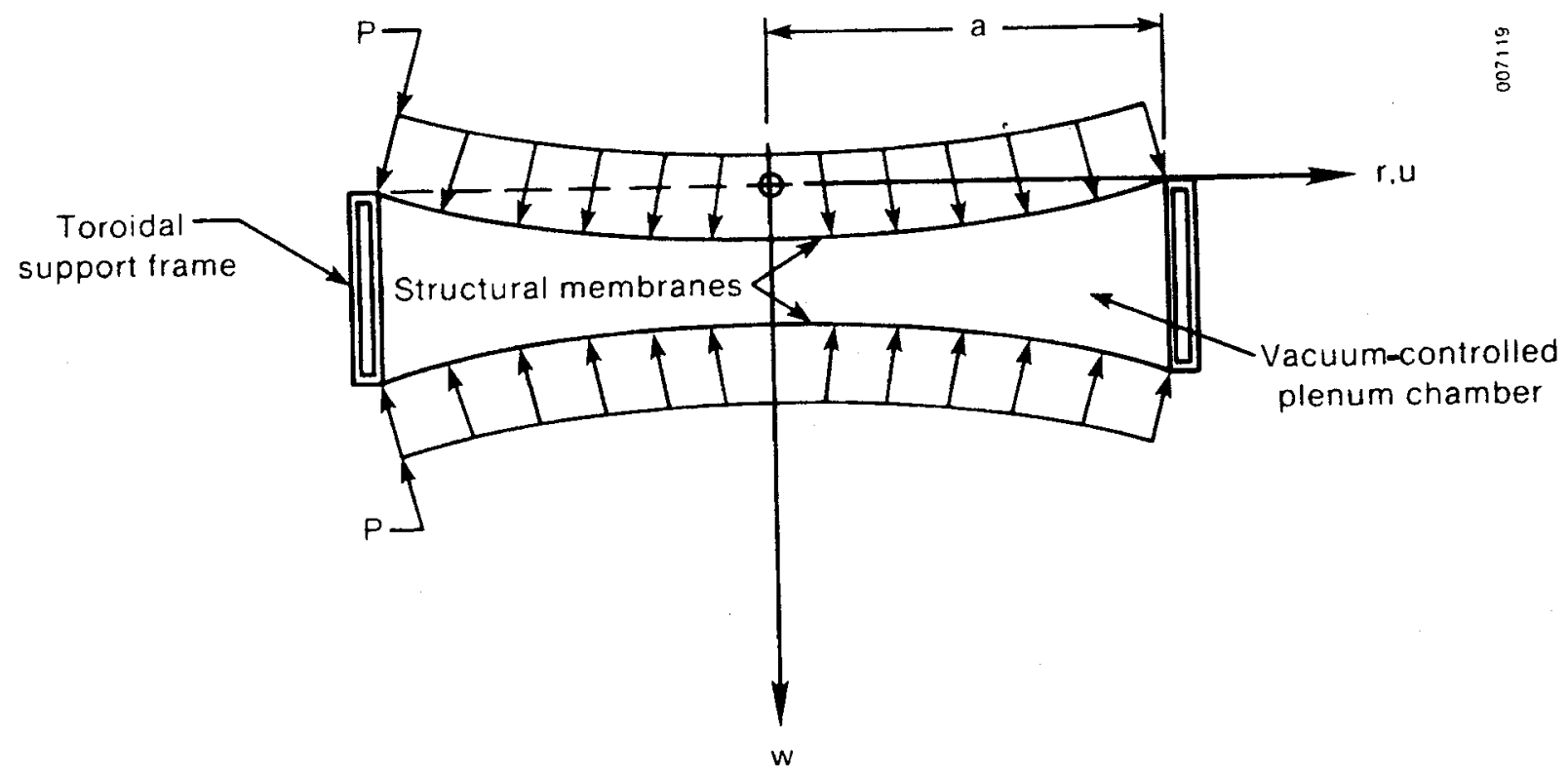

Reflector module geometry

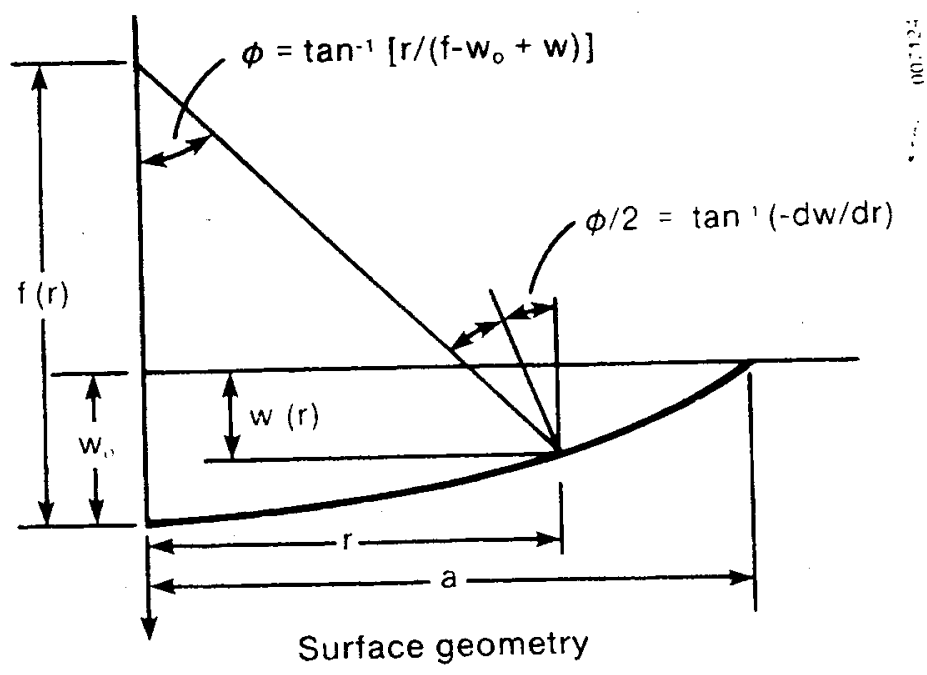

Figure 3-1. Geometry, Deformation, and Focal-Length Definitions for a StretchedMembrane Reflector Module 


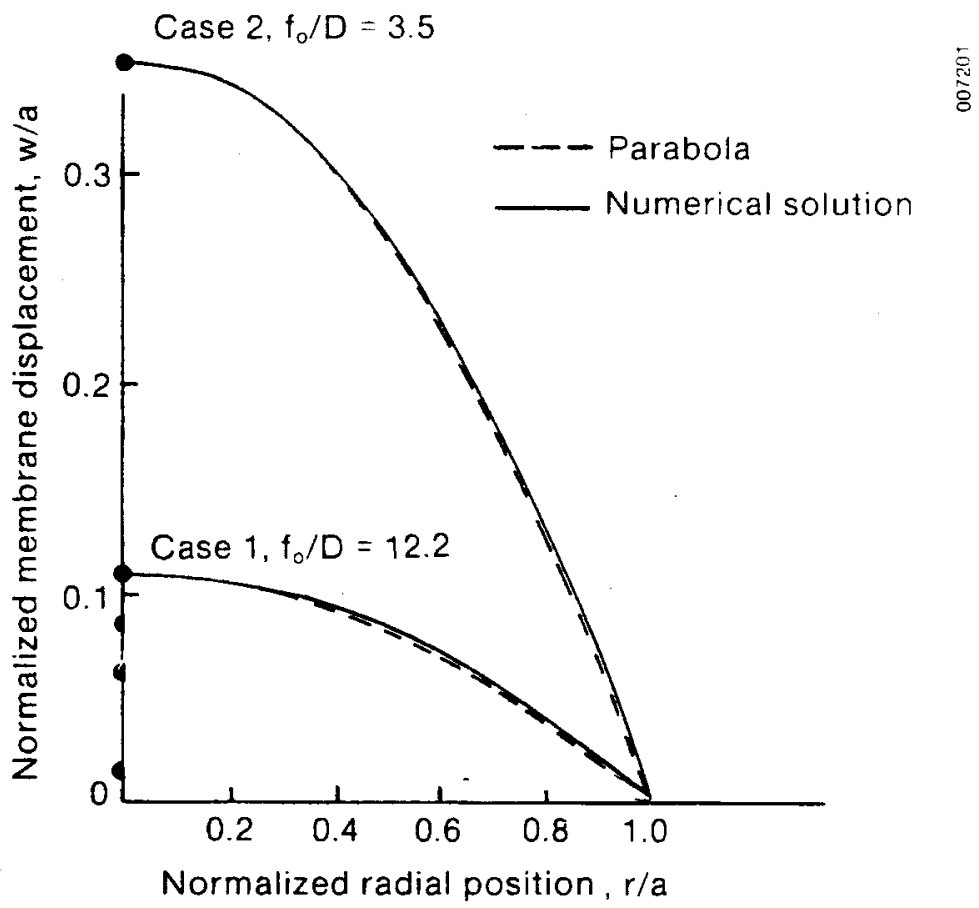

Figure 3-2. Predicted Normalized Membrane Displacement versus Normalized Radial Position Compared with a Perfect Parabola

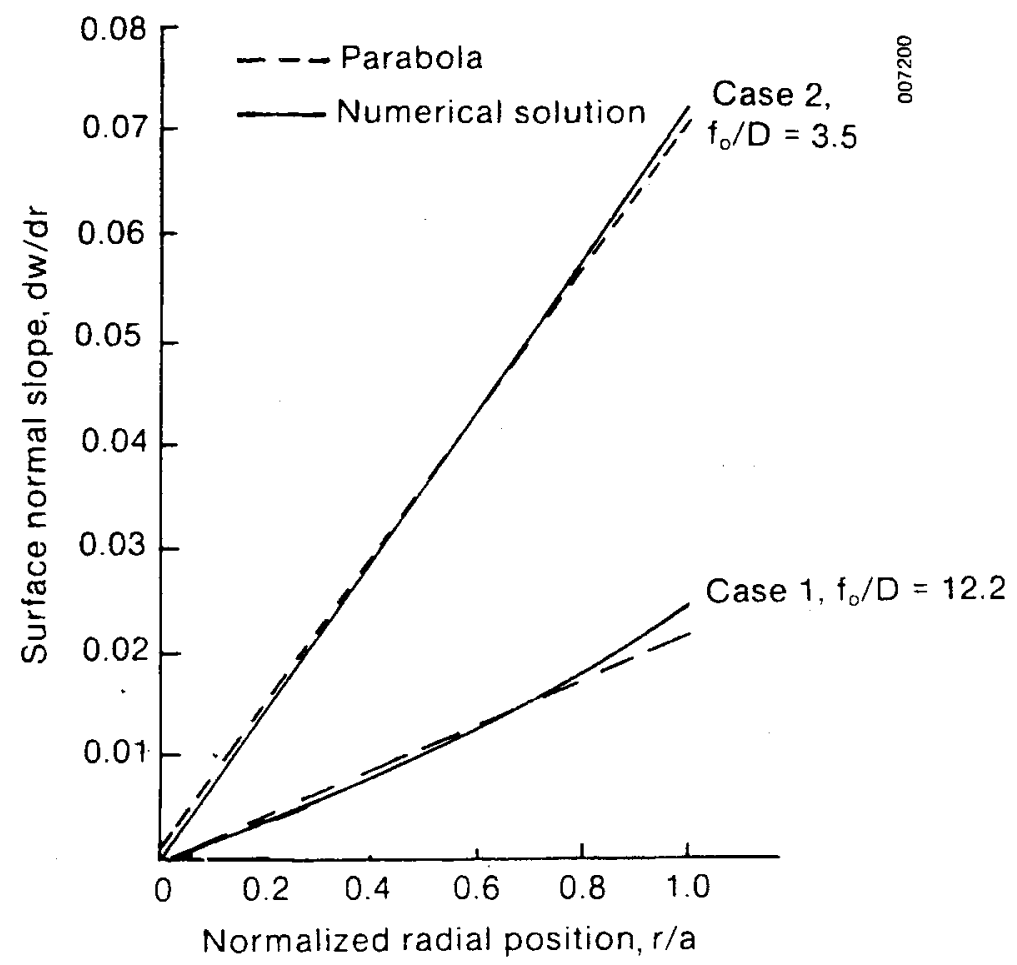

Figure 3-3. Predicted Surface Slope versus Normalized Radial Position Compared with a Perfect Parabola 


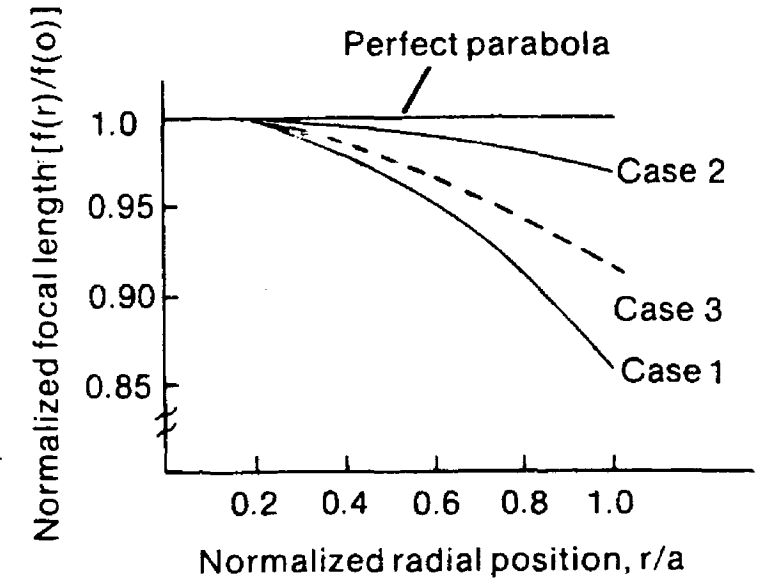

Figure 3-4. Predicted Normalized Focal Length versus Normalized Radial Position

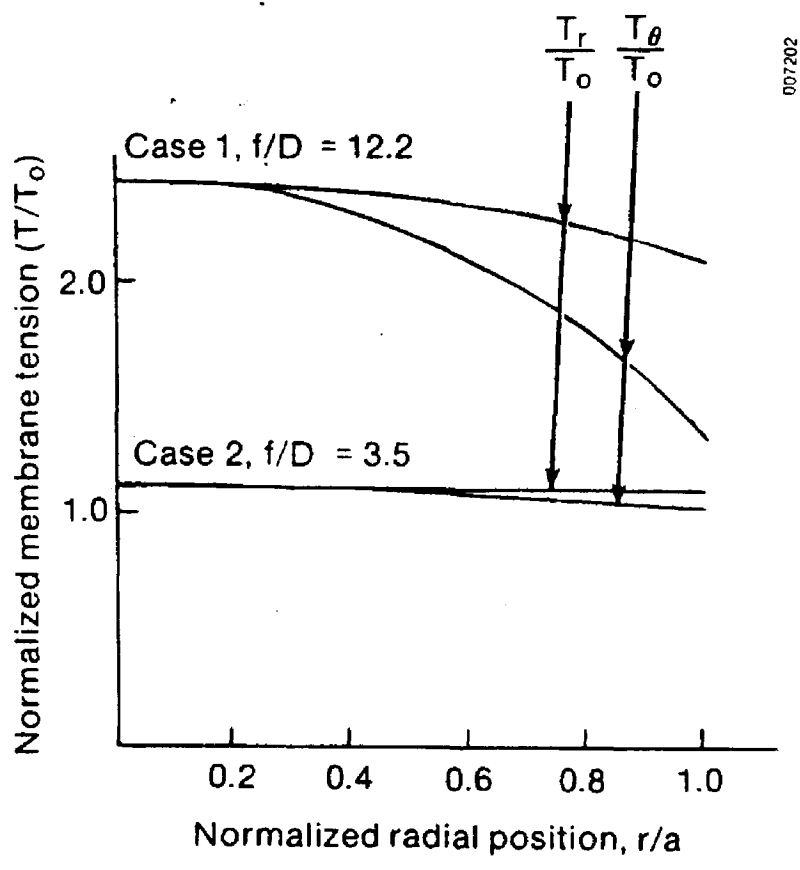

Figure 3-5. Predicted Normalized Membrane Tension versus Normalized Radial Position Corresponding to Cases 1 and 2 in Table 3-1

the long focal-length metal membrane design (compare the respective values of $\mathrm{Et} / \mathrm{T}_{0}$ in Table 3-1). As a further comparison, we also show in Figure 3-4 the predicted focallength pattern for Case 3, which assumes a polymer membrane similar to that used in Case 2 but with reduced tension $\left(T_{0}=350 \mathrm{~N} / \mathrm{m}\right)$ and increased thickness $(t=0.102 \mathrm{~mm})$; see Table 3-1. It is also interesting to note that the effects from the spherical shaping,

Table 3-1. Geometry and Material Properties of Elastic Membranes

\begin{tabular}{lcccccc}
\hline & \multicolumn{2}{c}{ Case 1 } & (Steel) & \multicolumn{2}{c}{ Case 2 (Polyester) } & \multicolumn{2}{c}{ Case 3 (Polyester) } \\
\hline E, GPa $\left(10^{6}\right.$ psi) & 209 & $(30)$ & 3.79 & $(0.55)$ & 3.79 & $(0.55)$ \\
$\mathrm{t}, \mathrm{mm}$ (in.) & 0.254 & $(0.010)$ & 0.051 & $(0.002)$ & 0.102 & $(0.004)$ \\
$\mathrm{T}_{\mathrm{o}}, \mathrm{N} / \mathrm{m}$ (lb/in.) & 4378 & $(25)$ & 1751 & $(10)$ & 350 & $(2)$ \\
$\mathrm{a}, \mathrm{m}(\mathrm{in})$. & 5 & $(197)$ & 0.762 & $(30)$ & 0.762 & $(30)$ \\
$\mathrm{f}_{\mathrm{o}} / \mathrm{D}$ & 12.2 & & 3.5 & & 3.5 & \\
$\mathrm{Et} / \mathrm{T}_{\mathrm{O}}$ & 12,000 & & 110 & & 1100 & \\
\hline
\end{tabular}

Source: Ref. 8. 
and from the elastic stress nonuniformity, lead to the same qualitative behavior in which the focal length is largest in the center and decreases monotonically to a minimum at the edge. Study of the membrane stresses gives us further insight into this issue as shown in Figure 3-5. We see in Figure 3-5 that for the metal-membrane case, the relative and absolute tension increments increase significantly both as a function of radial position and in the radial and circumferential directions. However, for the shorter focal-length polymer membrane, we see very little increase over the initial tension and hence fairly uniform stress contours in the membrane, both in direction and as a function of position. Thus, using equilibrium arguments, we see that the optical quality characteristics of the short focal-length reflector are better because of the nearly uniform stress state, which accrues primarily because of the low effective membrane stiffness, as noted earlier. With respect to Figure 3-5, and all the cases studied [8], note that the stress components peak in the membrane center and decrease monotonically with radius. Moreover, in all cases, the peak stress in the membrane center causes the elastically deformed membrane to be flatter in the center and have more curvature near the membrane edge than exists for either the spherical or desired parabolic optical shape.

As noted earlier, we looked at $\mathrm{f}_{\mathrm{o}} / \mathrm{D}$ values above 3.5 in Ref. 8 . In this particular case, it was shown (see discussion of Figure 2-2 in Section 2.0) that the deviation of a perfect sphere from that of a perfect parabola (in terms of focal-length variations) is extremely small. Hence, it is important to note that change in focal length [8], as seen in Figure $3-4$, is almost entirely due to the nonuniform stress distribution caused by the elastic deformation. This is seen by comparing the surface distortions relative to the desired parabolic shape caused by spherical shaping effects and those effects caused by nonuniform membrane stresses resulting from elastic deformation by plotting $\mathrm{f}_{\mathrm{e}} / \mathrm{f}_{\mathrm{o}}$ versus $f_{o} / D$ as in Figure 2-2. The results of this comparison are shown in Figure $3-6$, where an initially flat membrane was deformed elastically into an approximate sphere.

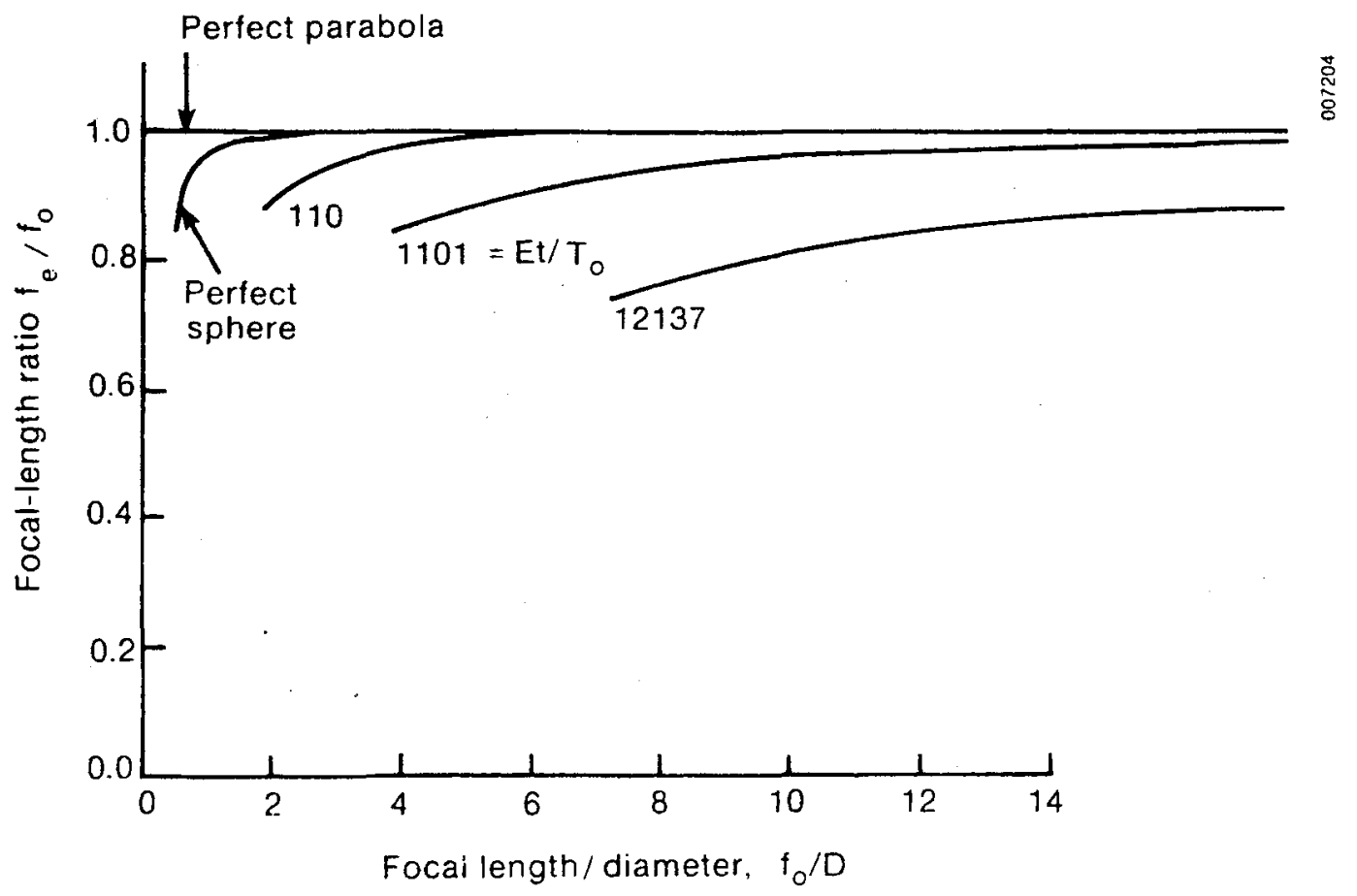

Figure 3-6. Membrane-Edge Focal-Length Change as a Function of Facet $f_{0} / D$ for the Three Elastic Membranes Described in Table 3-1, a Perfect Parabola, and a Perfect Sphere 
The membrane was assumed (1) 11 monam elastic during the entire deformation process and (2) to have a modulus equal $10: 1 \mathrm{hill}$ of steel even though a real steel membrane yields the smaller values of $\mathrm{f} / \mathrm{l}$, as shown in Figure 3-6. If we compare the results in Figure 3-3 with those in Figure 2-2, we see clearly that the focal-length deviation from the parabola caused by the clastic stress nonuniformities is considerably larger than the corresponding deviation caused by spherical aberrations (by almost two orders of magnitude down to $\mathrm{f}_{\mathrm{O}} / \mathrm{D}$ values of about 1.0 ). Further, if we investigate the variation between a perfect sphere and a perfect parabola, we do not see significant differences between the corresponding focal lengths until $f_{0} / D$ becomes smaller than about 2.0. Moreover, Figure 3-6 shows clearly the strong dependence of optical quality on $f_{0} / D$ and the dimensionless stiffness parameter $E t / T_{0}$. The deviation from the ideal parabola decreases with increasing $f_{0} / D$ and with increasing $E t / T_{0}$ (caused by low material moduli, small membrane thickness, and high membrane tension). 


\subsection{MEMBRANE SURFACE SHAPES CONSIDERING INELASTIC MATERIAL RESPONSE}

Before proceeding with the inelastic analyses, we will investigate the onset of inelastic effects and the limits to elastic membrane effects by using elastic analysis procedures. Subsequently, we will study the elastic/plastic deformation process of the pressureloaded membrane using the numerical finite-element procedure embodied in the ANSYS [19] computer code. Finally, note that one assumption, which we will use throughout this section unless otherwise noted, is that the initial tension in the membrane is zero. Since we will be concerned with generally very large deformations and hence strains, this assumption will have little impact on our results. We will address this point in more detail later.

\subsection{Limits on Elastic Response}

Consider first the limits on elastic deformations. We can use the analysis in Refs. 8 and 9 to obtain approximate values of stresses and strains attributable to pressure forming of the membrane surface. Further, from these analyses, we can make some simple geometric arguments that can help us understand the problems and issues (such as size and $\mathrm{f}_{0} / \mathrm{D}$ limitations) associated with the design and fabrication of large stretched-membrane modules with short focal lengths, as well as the elastic and plastic deformation regimes that might be anticipated. We will adopt the commonly used term dish concentrator for the short focal-length concentrators in subsequent discussions.

Figure 4-1 shows one approximation for average strain* versus the nominal $f_{0} / D \neq$ for an elastic membrane material based on the analysis developed in Ref. 8 . Here we see that for the ranges of $f_{o} / D$ 's that are typical of those corresponding to short focal-length dish concentrators, such as the U.S.-built test bed concentrator [15,16] and the German [1] dish designs (i.e., for $f_{o} / D$ 's between 0.6 and 0.8 ), a significant amount of strain exists in these membranes (i.e., between $1.5 \%$ and $3 \%$ strain on average). This indicates, as we will see more clearly later, that inelastic behavior is almost certain to occur with metal membrane materials in single-facet dish applications when the $f_{0} / D$ 's are typically below 2.0. This is because the strain to yield for typical steel materials is about $0.1 \%$ to $0.15 \%$, whereas for typical aluminum materials, the strain to yield is on the order of $0.3 \%$ to $0.35 \%$.

In Figure 4-2, we show the peak-forming stress in an elastic membrane as a function of nominal $f_{o} / D$ for the membrane surface. The peak-forming stress is the stress that occurs in the membrane center because of its shape change, when the initial pretension in the membrane is not considered. Four points are illustrated in this particular figure. First, with increasing $\mathrm{f}_{\mathrm{O}} / \mathrm{D}$, the peak-forming stress for the different materials rapidly decreases. Second, we see that as the modulus of the materials increases, the peakforming stress for a given $\mathrm{f}_{0} / \mathrm{D}$ increases proportionately. Further, when we consider aluminum material with a modulus of $77 \mathrm{GPa}\left(11 \times 10^{6} \mathrm{psi}\right)$ and steel with a modulus of $207 \mathrm{GPa}\left(30 \times 10^{6} \mathrm{psi}\right)$, along with typical yield stresses for these materials, it is obvious

* A single uniform average strain over the membrane was assumed, and its amplitude was determined using the principle of minimum potential energy.

$\ddagger$ We will use the term $f_{0} / D$ as a measure of the nominal $f / D$ for the dished surface. 


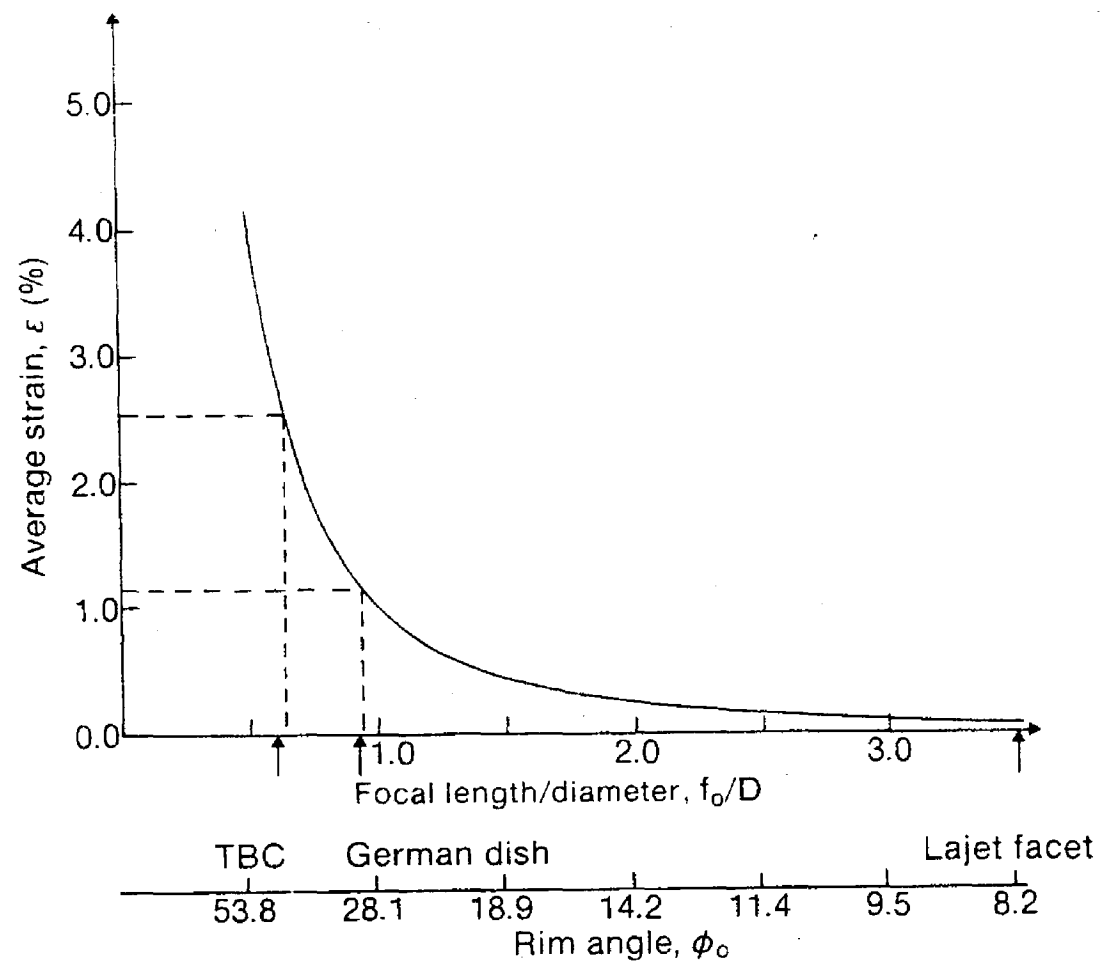

Figure 4-1. Average Membrane-Forming Strain versus Nominal $\mathrm{f}_{\mathrm{o}} / \mathrm{D}$ and Rim Angle Based on Membrane-Center Focal Length

that steel membranes will typically yield at $f_{0} / D$ levels that are below approximately 3.5. In addition, aluminum membranes will probably yield below $f_{\rho} / D$ levels of about 2.0 to 2.5. With polymer materials, however, because of the relatively low modulus, it may be possible to reach significantly lower $f_{0} / D$ 's while maintaining elastic response. Clearly, from the shape of these curves, it appears that it would be very difficult to make any kind of a totally elastic membrane dish design having an $f_{0} / D$ below 1.0 regardless of the membrane material used.

Using the information in Figures 4-1 and 4-2, we see that anticipated average strains for typical single-module dish designs are fairly large (about $3 \%$ for $f_{0} / D$ values of about 0.6). This implies that membrane materials will have to be fairly ductile, having a significant strain-to-failure capability, possibly one that is considerably larger than the average strain. This indicates a need for either ductile aluminum or ductile stainless steel alloys if common metals are selected for the membrane and if small $\mathrm{f}_{\mathrm{o}} / \mathrm{D}$ designs are desired. Further, for these thin-membrane sheets, local necking of the material may lead to catastrophic tears unless good ductility is present. This is an especially important issue since for many metals strain-to-failure often decreases with membrane thickness. Note, however, that work hardening, which is operative in many candidate membrane metals, can help deter catastrophic necking and tearing. Note also that although many polymer and composite materials exhibit large elastic strain capabilities, rupture failure often (though not always) occurs at the onset of plastic yielding. Hence for many of these polymer materials, plastic flow is not an option. 


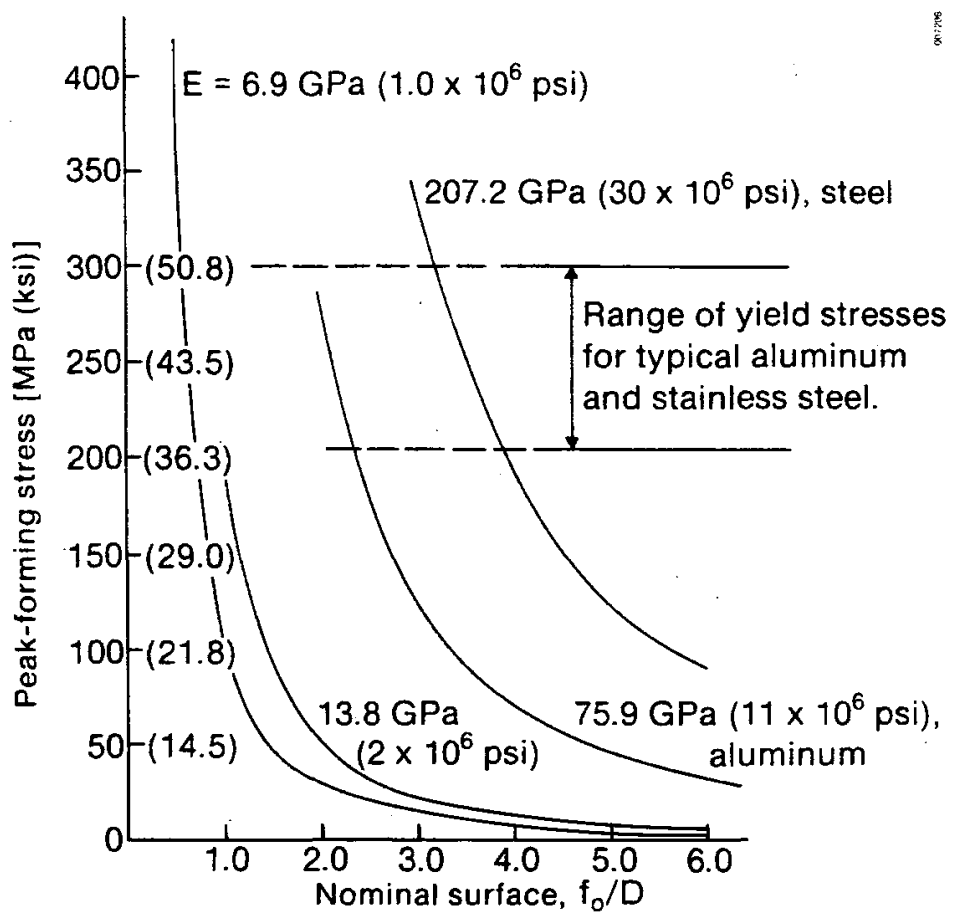

Figure 4-2. Peak-Forming Stress (in Membrane Center) as a Function of NominalFacet $\mathbf{f}_{\mathbf{o}} / \mathrm{D}$

\subsection{Large Deformations Accompanied by Inelastic Material Response under Increasing Loads}

Figures 4-3 through 4-14 describe some of the results from the analysis of large, finite axisymmetric membrane deformations with inelastic material response. These analyses of pressure-induced, finite-deformation, shape-forming processes were carried out using the finite-element code ANSYS [19], which is widely used in the structural engineering community. In these analyses, an axisymmetric, conical shell element was used and the deformations of the nodal points were calculated. Local-surface curvatures, slope, and focal-length predictions were determined by using the ANSYS predicted surface nodal displacements along with a central finite difference scheme to determine the higher derivatives. The assumptions used in the inelastic analysis are similar to those used for the elastic analysis except that the membrane material is assumed to exhibit bilinear material response; i.e., elastic response followed by nearly perfect, or perfectly plastic, response. The inelastic analyses were performed for a steel $(7.5 \mathrm{~m}$ radius) membrane having the geometric and material properties described in Table 4-1. Further, as in the elastic examples, the membrane is assumed to be attached to a perfectly rigid boundary attachment. It is clear that this inelastic material response, described more fully later, is nonlinear and nonconservative and that the final deformation, stress, and strain states will depend on the loading history. Thus, the deformation process described here using ANSYS considers both geometric and material nonlinearities. 


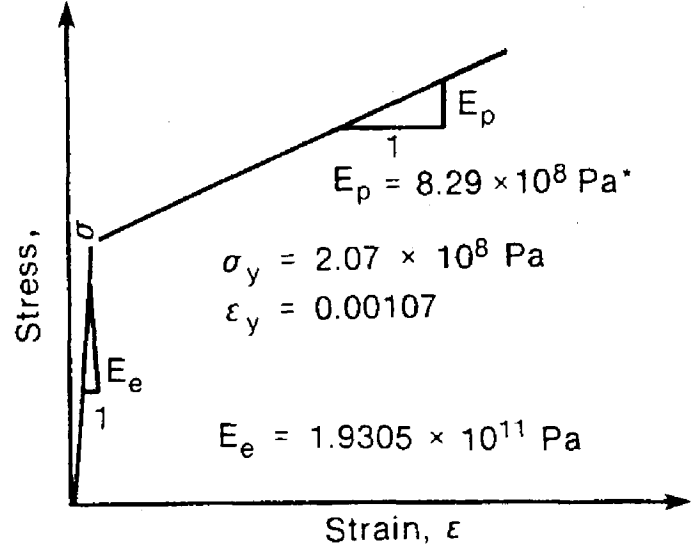

* For elastic, perfectly plastic materials (i.e., without work hardening), $E_{p}=0$

(a) Idealized stress strain curve used for inelastic analyses for No. 303 stainless steel

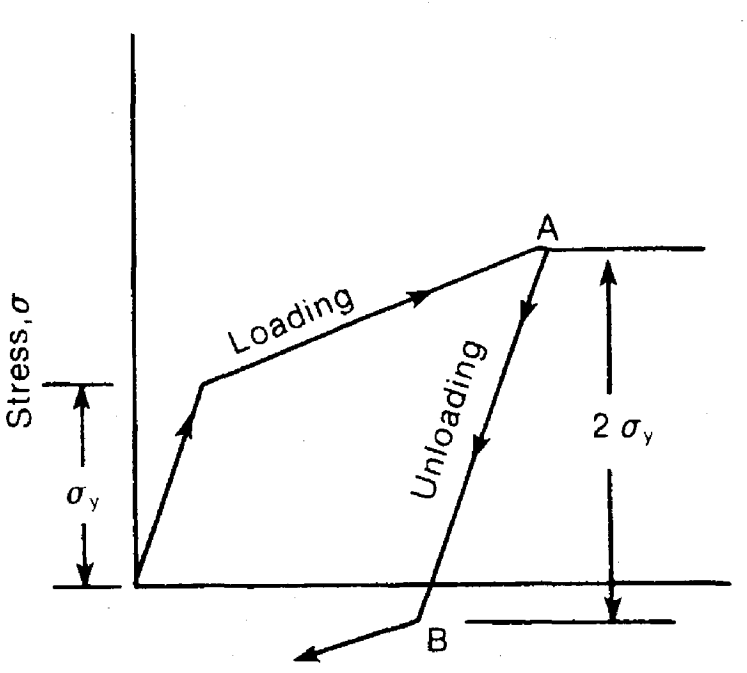

(b) Kinematic work-hardening assumption used in inelastic analyses

Figure 4-3. Material Model Idealizations of Stress/Strain Material Response Assumed for Inelastic Analyses

For all the inelastic analyses performed, a uniform pressure of $500 \mathrm{~Pa}$ was first applied on the membrane surface. The material response was elastic at this load level. The pressure load was then increased to $900 \mathrm{~Pa}$, at which level the material at membrane center just began to yield. Inelastic material response became operative thereafter and

Table 4-1. Geometric and Material Property/Response Assumptions Used in the Inelastic Analyses

\begin{tabular}{lcc}
\hline \multicolumn{1}{c}{ Membrane Material } & 303 Stainless Steel ${ }^{\mathrm{a}}$ & $\begin{array}{c}\text { Elastic/Perfectly } \\
\text { Plastic Case }\end{array}$ \\
\hline Membrane radius, m & 7.5 & 7.5 \\
Membrane thickness, mm & 0.254 & 0.254 \\
E, elastic modulus, GPa & 193.050 & 193.050 \\
E $_{\text {p plastic modulus, GPa }}$ & 0.829 & 0 \\
Yield stress, MPa & 207.000 & 207.00 \\
Yield strain & 0.001 & 0.001 \\
Ultimate stress, MPa & 620.000 & 207.00 \\
Ultimate strain & 0.50 & 0.50 \\
\hline
\end{tabular}

asource: Ref. 21. 
the pressure load was gradually increased to a peak-forming pressure of $3000 \mathrm{~Pa}$ in increments of $300 \mathrm{~Pa}$. Further, the pressure was gradually reduced to $1000 \mathrm{~Pa}$ in load steps of $500 \mathrm{~Pa}$ after the peak load was reached, to study the impact of unloading on the optical performance of the membrane surface. We were not able to obtain a stable solution with ANSYS with work-hardening or non-work-hardening material response when the pressure was significantly above $3000 \mathrm{~Pa}$.

Inelastic material response can, in general, be described by using an appropriate yield criterion, a flow rule, and a hardening law. The von Mises yield criterion [20] was used in this analysis with ANSYS, which includes the effects of finite deformations and rotations. The assumed flow rule used in these analyses is the one derived by Prandtl-Reuss [20], in which no volumetric plasticity will occur. Consistent with the von Mises yield criterion and the Prandtl-Reuss flow rule, the concept of equivalent strains is used and is employed in subsequent discussions to conveniently reduce the general multidimensional stress/strain states in the body under consideration to those associated with a uniaxial stress/strain relation, such as that provided by a simple uniaxial tensile-test. Theoretical developments of the equivalent strain description using the Prandtl-Reuss flow rule are found in Ref. 20. Material stress stiffening was modeled using the kinematic workhardening description [20]. Kinematic work hardening is characterized as in Figure 4-3b where, if the material has yielded and then unloads (see point $A$ in Figure 4-3b), the stress level must be reduced by a value of two times the elastic yield before yielding in the reverse direction will occur (see point $B$ in Figure 4-3b). Further, the parameters chosen for the kinematic work hardening as given in Table 4-1 correspond to 303 stainless steel [21]. Those corresponding to the elastic/perfectly plastic (non-work-hardening) material response are identical to the stainless steel parameters except that the plastic modulus is set to zero. We will use these two sets of parameters to define the effects of work hardening on the large deformation process. In the analysis up to this point, we have used $f_{0}$ to characterize the focal length of the surface and to normalize the results since the maximum focal length has occurred at the vertex (this is always the case in elastic analyses). When large deformations are accompanied by inelastic material response, an inelastic region starts to develop from the center proceeding toward the edge of the membrane as the pressure load is increased. This central part of the membrane deforms closely into a parabolic shape, which provides a broad, nearly constant, focal-length region between the center and the membrane edge. Hence, in subsequent discussions, we will use $f_{p}$ to denote this peak focal length as a measure of the nominal focal length of the surface.

In Figure 4-4, we illustrate the predicted required applied pressure to deform the membrane to a given $f_{p} / D$ for the work-hardening (i.e., 303 stainless steel) case and the nonwork-hardening (i.e., elastic/perfectly plastic) case.* Here we see the dramatic increase in pressure required to reach very small $f_{p} / D$ 's. This is caused primarily by the shapeinduced stiffness effect, since the more curved the shape is the more the membrane can support the applied pressure load like a shell. The effect of work hardening is also seen at small $f_{p} / D$ 's where, because of the increased material stiffness, somewhat more pressure loading is required for the work-hardening case. The work-hardening effect is quite small primarily because the plastic modulus in the work-hardening case are relatively small compared to the elastic modulus (i.e., $E_{p} / E=0.0043$ ).

*It can be easily shown that, for a rigid/perfectly plastic material,

$$
P \cdot(f / D)=\left(\sigma_{y} \cdot t\right) / D
$$

and that this relation provides a reasonable approximation to the curves shown in Figure 4-4. 
In Figure 4-5, we show the equivalent strains as a function of nominal $f_{p} / D$, corresponding to the membrane center and at the membrane edge for both the workhardening and non-work-hardening material-response assumptions. The peak equivalent strain occurs at the membrane center while the minimum equivalent strain occurs at the membrane edge. Each of these curves shows the same general trend with $f_{p} / D$ as in Figure 4-4. We see that the differences between the equivalent strains in the center and at the edge are considerably different and increasingly so at small $f_{p} / D$ 's, whereas at large $f_{p} / D$ 's they are fairly similar. Further, we see that the impact of work hardening is hardly detectable until small $\mathrm{f}_{p} / \mathrm{D}$ 's are reached. We can also see the cause of these differences by investigating the associated stress distributions, which will be discussed later. Also in Figure 4-5, we see that the peak-equivalent strain versus $f_{p} / D$ curves for membranes considered in this work are very similar to the elastic curve described in Figure 4- 1 . This similarity is essentially attributable to compatibility requirements that govern the permissible strain-displacement relationships. Further, Figure 4-5 shows that yielding begins (i.e., equivalent strain $>0.1 \%$ microstrain) at the membrane center at an $f_{p} / D$ value of about 4.2 , which agrees with the information given in Table 4-1 and Figure 4-2.

In Figure 4-6, we have plotted the yield locus as a function of applied pressure and normalized radial position. The yield locus is the maximum radial distance measured in the plane of the membrane surface, from the center, out to which yielding has occurred for a given pressure loading, for both the work-hardening and non-work-hardening cases; the differences between the two loci corresponding to work hardening and non-work hardening were extremely small and are not detectable on the scale presented. We see in Figure 4-6 that no yielding occurs until the pressure reaches about $900 \mathrm{~Pa}$. Beyond pressure loadings of about $900 \mathrm{~Pa}$, however, the yield surface moves rapidly

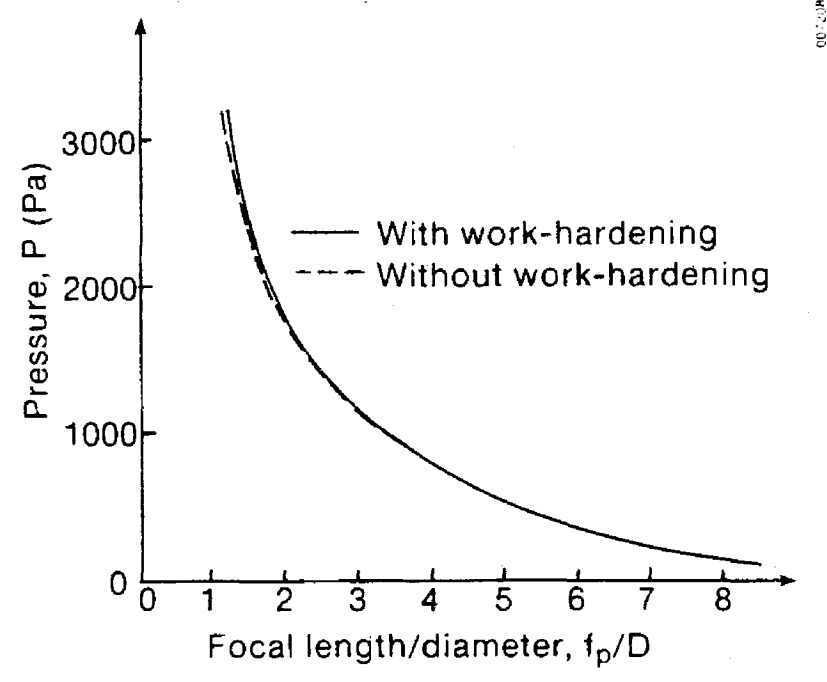

Figure 4-4. Pressure as a Function of Nominal $f_{p} / D$ for Work-Hardening and Non-Work-Hardening (Perfectly Plastic) Material Response

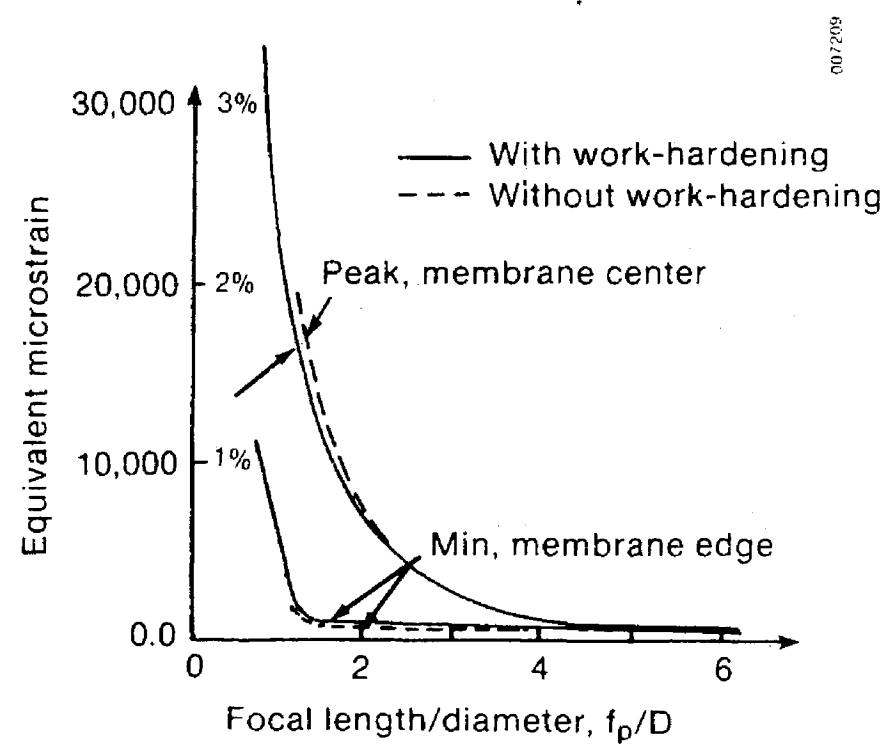

Figure 4-5. Peak and Minimum Equivalent Strains as a Function of Nominal $f_{p} / D$ for Work-Hardening and Non-WorkHardening Material Response 


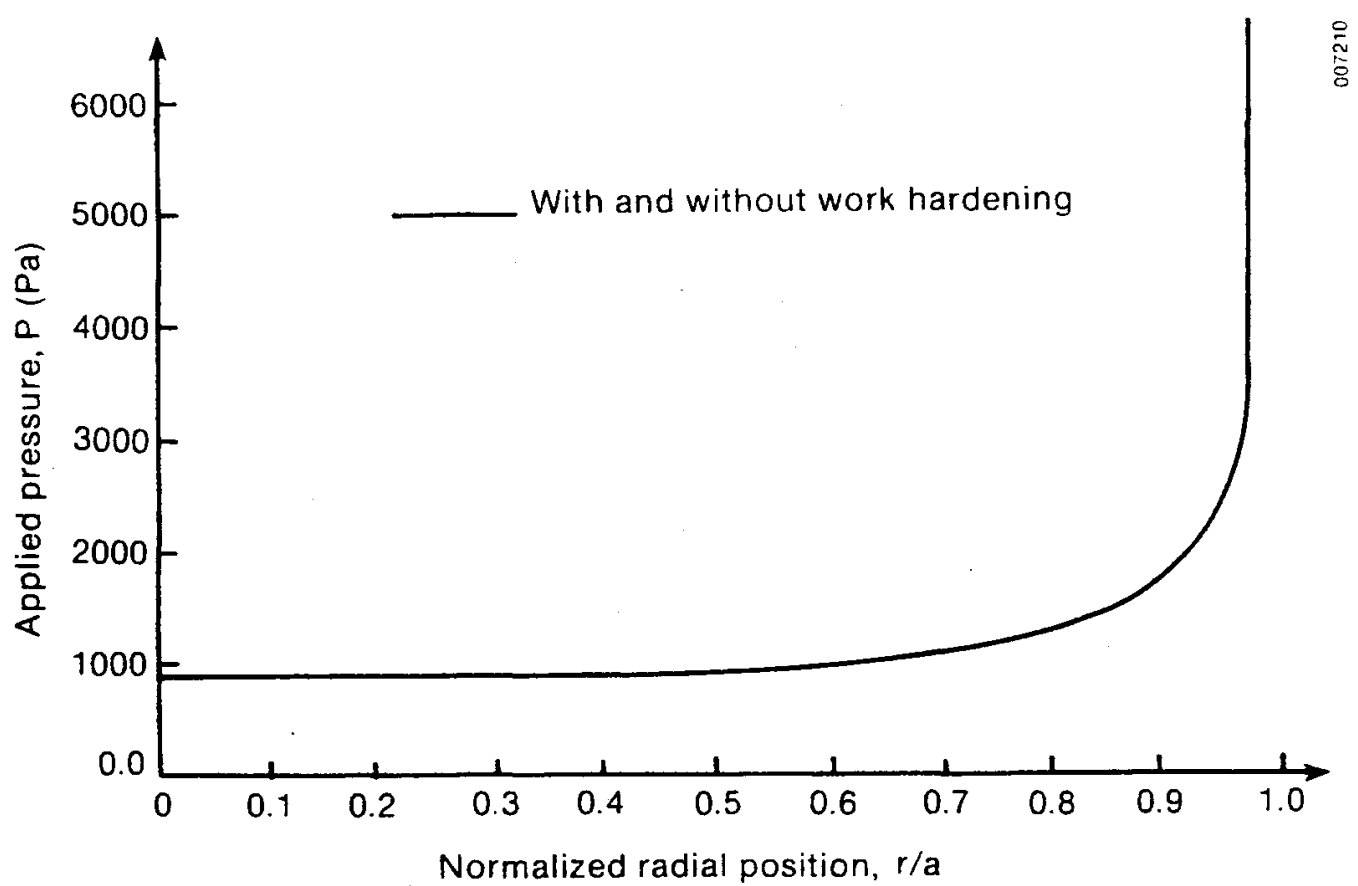

Figure 4-6. Membrane Material Yield Locus as a Function of Normalized Radius for Work-Hardening and Perfectly Plastic Material Response

toward the radial fixed attachment at a normalized radius of 1.0 (i.e., $r / a=1.0$ ) with very little increase in pressure. However, at a normalized radius of about 0.85 , a significant pressure rise is needed to extend the plastic yield zone toward the radial constraint. This is consistent with the drop-off of the circumferential and radial stress components (for the loading cases corresponding to $1500 \mathrm{~Pa}$ and below) as a function of increasing radius, as we see in Figures 4-7 and 4-8.

Figure 4-7 illustrates the circumferential membrane stress component in the membrane as a function of nondimensionalized radial position $\mathrm{r} / \mathrm{a}$ for various levels of pressure for both work-hardening and perfectly plastic material response assumptions. Here we see that when the membrane is still elastic at an applied pressure of $500 \mathrm{~Pa}$, a significant variation in the circumferential stress occurs as a function of radial position, which is similar in nature to the stress profiles shown in Figure 3-5. At $900 \mathrm{~Pa}$, however, the membrane has yielded and the stress contour is fairly flat up to a normalized radius of about 0.35 . At $1500 \mathrm{~Pa}$, a much greater amount of plastic yielding has occurred and the membrane stress contour is again quite flat, now out to a normalized radius of approximately 0.80 . In addition, the effect of work hardening is evident in Figure 4-7 by comparing the work-hardening and non-work-hardening cases directly for the different loading conditions. The difference between the work-hardening and non-work-hardening stress contours corresponding to $900 \mathrm{~Pa}$ is quite small since at this pressure very little plastic flow has occurred. At $1500-\mathrm{Pa}$ loading, about four times as much plastic straining has occurred (see Figures 4-4 and 4-5) in the center and the effect becomes quite noticeable. Also, at $1500 \mathrm{~Pa}$, the work-hardening and non-work-hardening curves converge at large radii where the plastic flow is much smaller. At $3000 \mathrm{~Pa}$, the effects of work hardening are much more noticeable in the membrane center region. Further, at a pressure loading of $3000 \mathrm{~Pa}$, significant yielding occurs all the way out to the edge and a rapid drop-off in stress does not occur as in the loading cases of $1500 \mathrm{~Pa}$ and below. The circumferential constraint at the attachment retards the plastic flow at moderate pressure loadings. 


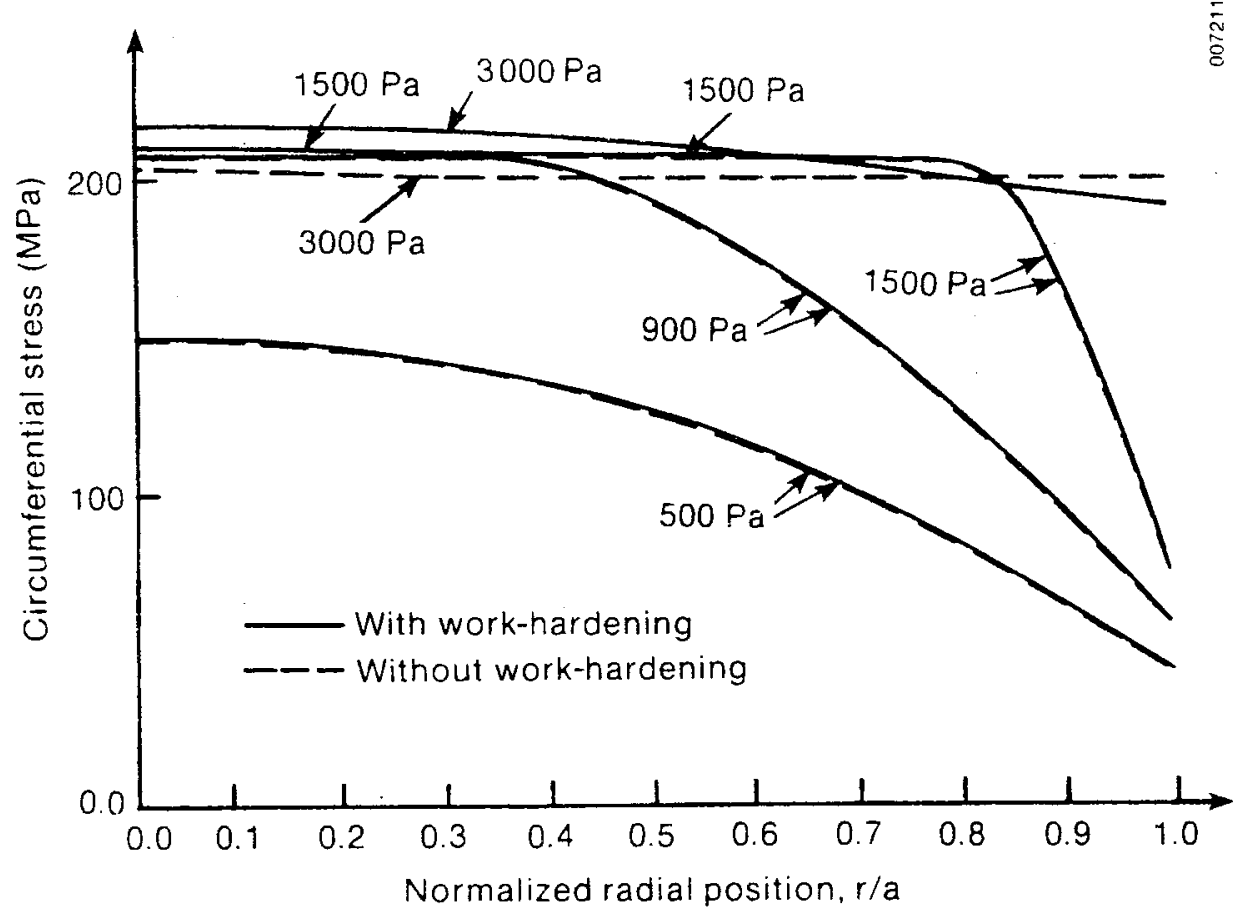

Figure 4-7. Circumferential Stress as a Function of Normalized Radius for Both Work-Hardening and Non-Work-Hardening Material Response

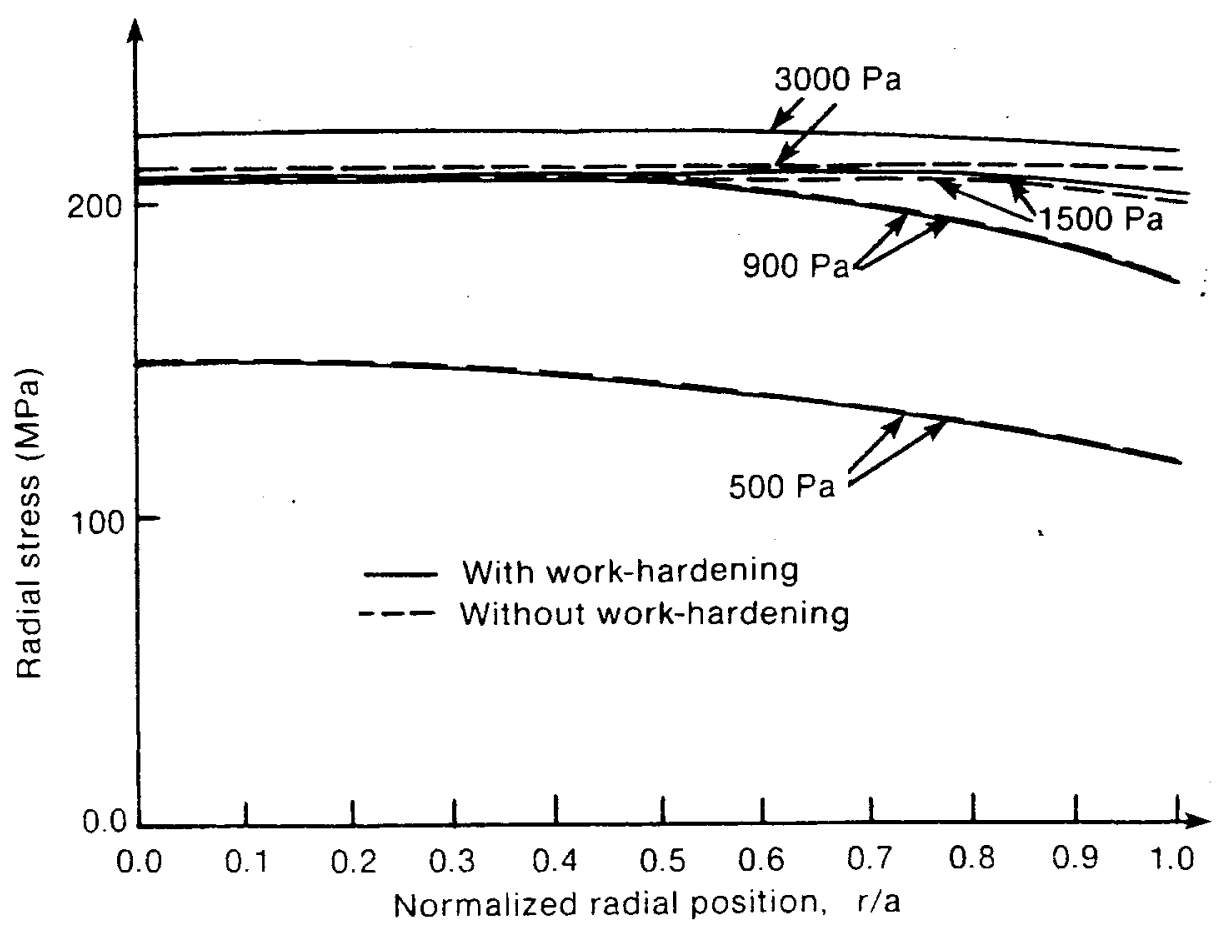

Figure 4-8. Radial Stress Variation as a Function of Normalized Radial Position for Both Work-Hardening and Perfectly Plastic Material Response 
In Figure 4-8, the radial membrane stress component is shown as a function of the normalized radius for the same pressure levels described in Figure 4-7. Here again, we see effects similar to those described in Figure 4-7 except that the variation with radial position is not nearly as great for any of the cases considered. Again, this is consistent with the findings from the elastic analyses, where the variation in the circumferential stress for a given loading was significantly greater than the variation corresponding to the radial stress distribution. This finding is essentially caused by the displacement compatibility constraint caused by boundary condition at the membrane edge.

Note that, with respect to Figures 4-7 and 4-8, the rapidly increasing nonuniform stress state near the membrane edge can cause curvature variations relative to the center region where the stress is fairly uniform. Thus the membrane surface region near the fixed edge will have more curvature than the membrane center region.

The nonuniformity in both components of membrane stress as caused by the support.constraint is accompanied by nonuniform slopes especially near the membrane edge support. The membrane slope, as a function of dimensionless ratios $(\mathrm{r} / \mathrm{a})$, is shown in Figure 4-9. The local slopes, curvatures, and focal length of the membrane were calculated using the procedure described in Appendix A accounting for finite in-plane stretch as well as the out-of-plane deflection of the membrane. The behavior shown in Figure 4-9 is similar to that that occurs in the elastic cases. Here it is clearly seen that the slope of the membrane is quite linear until a dimensionless value of about 0.7 is reached. This indicates that the membrane deforms into a nearly parabolic shape up to

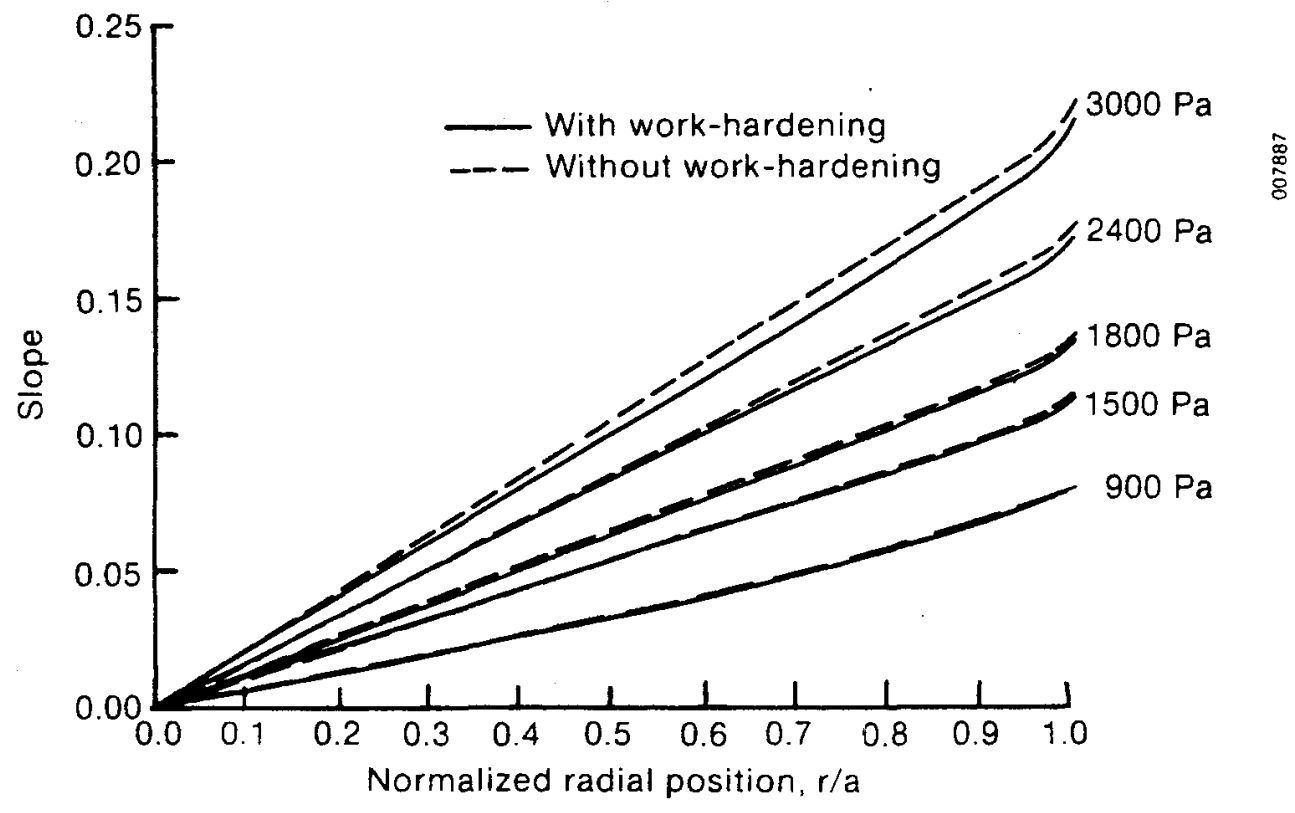

Figure 4-9. Surface Slope versus r/a for Both Work-Hardening and Non-WorkHardening Material Response Corresponding to Five Levels of Pressure Loading 
this radial position. Thus, we expect the curvature to be quite constant with $\mathrm{r} / \mathrm{a}$ until a level of $\mathrm{r} / \mathrm{a}=0.7$ is reached. At $\mathrm{r} / \mathrm{a}$ values greater than 0.8 , a significant change in slope is quite visible. Close scrutiny of Figure 4-9 also indicates little impact of workhardening (for the cases considered) as a function of radial position. Moreover, workhardening effects become most noticeable at higher pressure levels, and at these higher pressure levels (and hence higher levels of plastic deformation) the slope is more linear out to higher values of $\mathrm{r} / \mathrm{a}$ with higher levels of load and plastic deformation.

The curvature response of the membrane is shown more clearly in Figures 4-10 and 4-11 (corresponding to work-hardening and non-work-hardening material response cases, respectively). In these figures, surface curvature* versus normalized radius $(\mathrm{r} / \mathrm{a})$ for $\mathrm{dif}$ ferent applied pressures is presented. In both figures it is seen that curvatures vary significantly because of nonuniform elastic stress distribution at pressures less than the yielding pressure, $900 \mathrm{~Pa}$. As the pressure exceeds $900 \mathrm{~Pa}$, the membrane surface deforms over much of the surface to a shape that closely approximates a sphere having a constant curvature. Also, by comparing Figures 4-10 and 4-11, we can see that for pressure levels above $900 \mathrm{~Pa}$, the curvature for the work-hardening case is less than in the non-work-hardening cases. This is caused by the work hardening and the associated stress nonuniformities that grow significantly at larger pressures and deformations.

For the same cases described in Figures 4-10 and 4-11, we can determine the focal length as a function of radial position. This is shown in Figure 4-12 as normalized focal length versus normalized radial position, where the membrane-edge response is very similar to the elastic case as described in Figure 3-4. We see that once yielding occurs (i.e., $P>900 \mathrm{~Pa}$ ) the focal length becomes much more uniform, and the best uniformity exists at $1500 \mathrm{~Pa}$. At $3000 \mathrm{~Pa}$, the uniformity falls off somewhat, partly because of spherical aberration effects. In addition, we see that the non-work hardening (at $\mathrm{P}=3000 \mathrm{~Pa}$ ) gives greater uniformity as would be expected because of the more uniform stress state in the membrane. We can gain further insight into these membrane response effects in another manner by describing the response as in Figures 2-2 and 3-6.

In Figure 4-13, we show the ratio $\left(f_{e} / f_{p}\right)$ of the focal length at the membrane fixed edge to the nominal center focal length of the membrane $f_{p}$ as a function of nominal $f_{p} / D$. Three cases are considered in Figure 4-13. In the first lase, the membrane is subject to an initial tension of $10,500 \mathrm{~N} / \mathrm{m}(60 \mathrm{lb} / \mathrm{in}$.) and then to additional pressures applied on its surface. Here we see that the correlation between the edge focal length and the nominal focal length becomes poorer as $f_{p} / D$ decreases until the material yields at an $f_{p} / D$ of about 5.4, where inelastic deformations become predominant. The two lower curves in Figure 4-13 correspond to the case where no initial tension was induced in the membrane before the pressure was applied. Once the material yields, the surface shape becomes more spherical (on average). The agreement between the edge focal length and nominal focal length improves until the difference between the sphere and parabola becomes the more dominant effect, as described in Figure 2-2. Also, the second and the third cases show the effect of work-hardening and non-work-hardening on the peak focal-length variation. Figure 4-13 shows a slight benefit for perfectly plastic material response compared to a work-hardening material response for a small $f_{p} / D$ design (i.e., $<2.0$ ). Perfectly plastic material response provides a slightly better $\mathrm{f}_{\mathrm{e}} / \mathrm{f}_{\mathrm{p}}$ in this regime since a more uniform stress distribution results. Note also that, in the elastic design range, a membrane with no initial tension provides a lower value of $f_{e} / f_{p}$ than does one with

* Surface curvature is defined as the inverse of the local radius of curvature. In this case, we looked at only the radial direction. A perfectly spherical shape would have a constant surface curvature. 


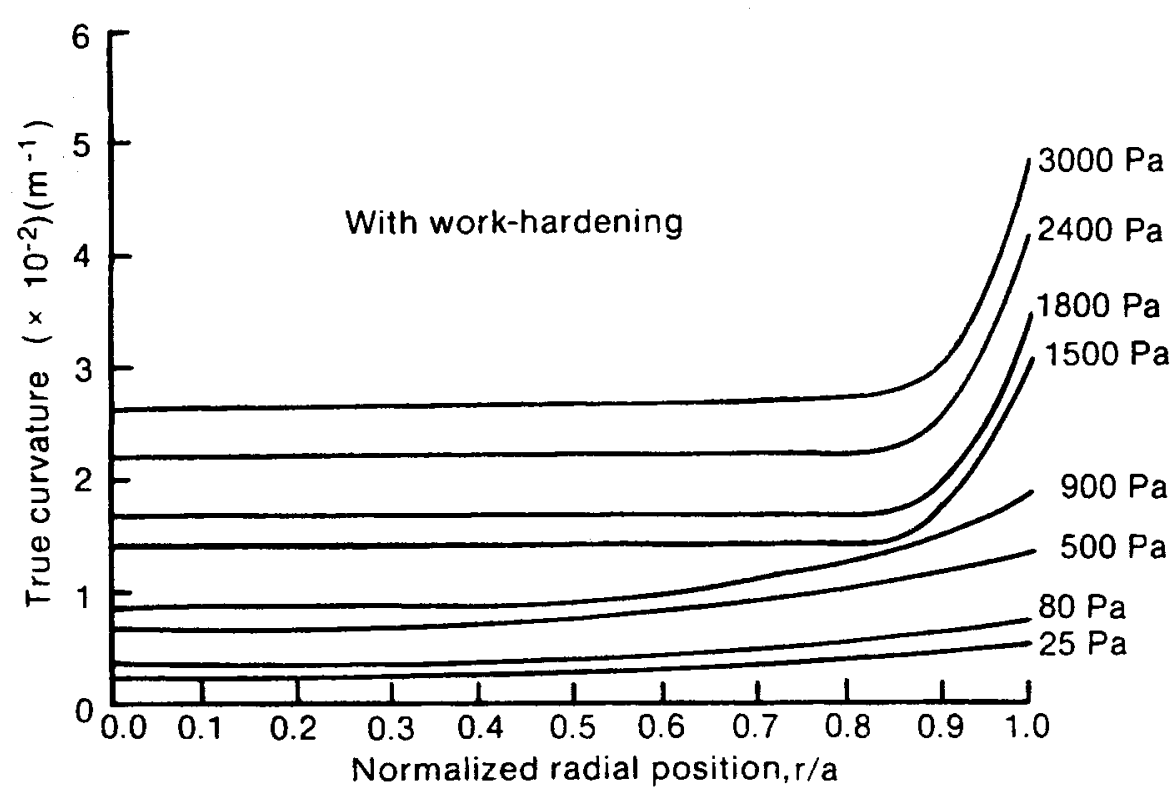

Figure 4-10. Local Surface Curvature as a Function of Normalized Radius Corresponding to Work-Hardening Material Response and Applied Pressures

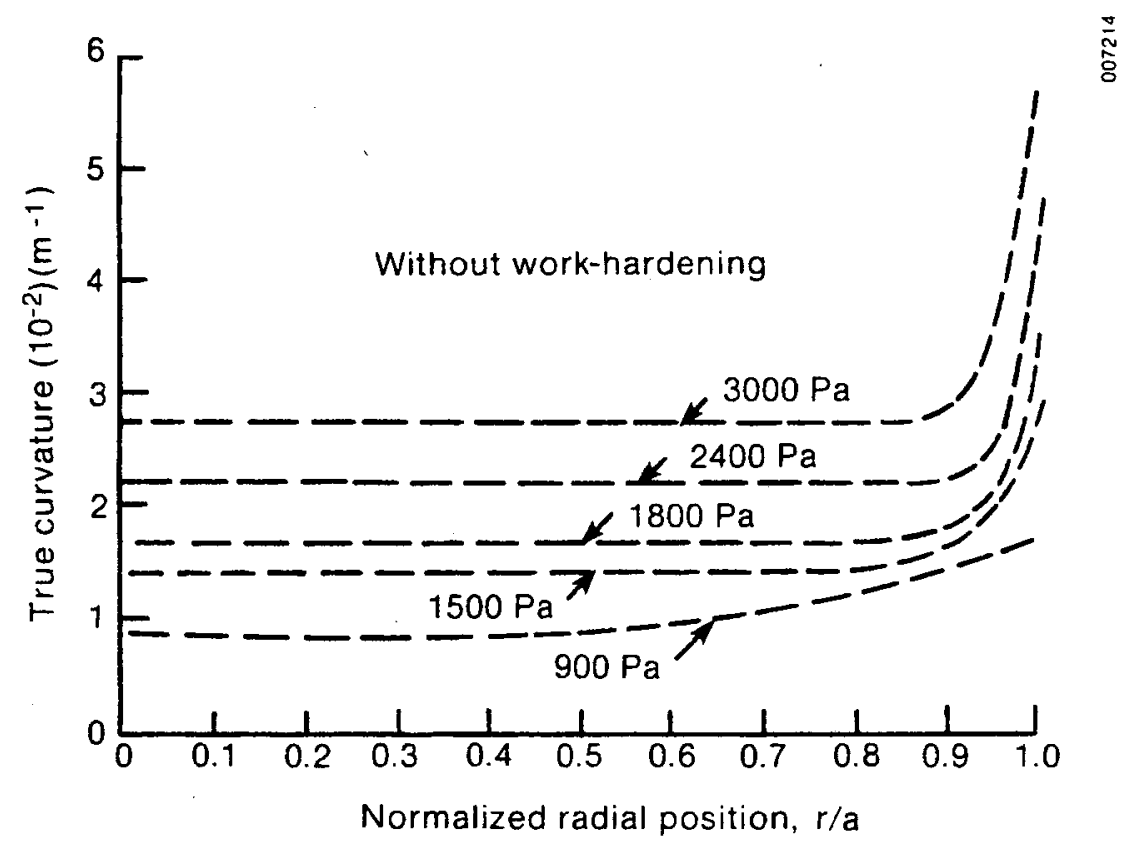

Figure 4-11. Local Surface Curvature as a Function of Normalized Radius for Perfectly Plastic Material Response and Applied Pressures 


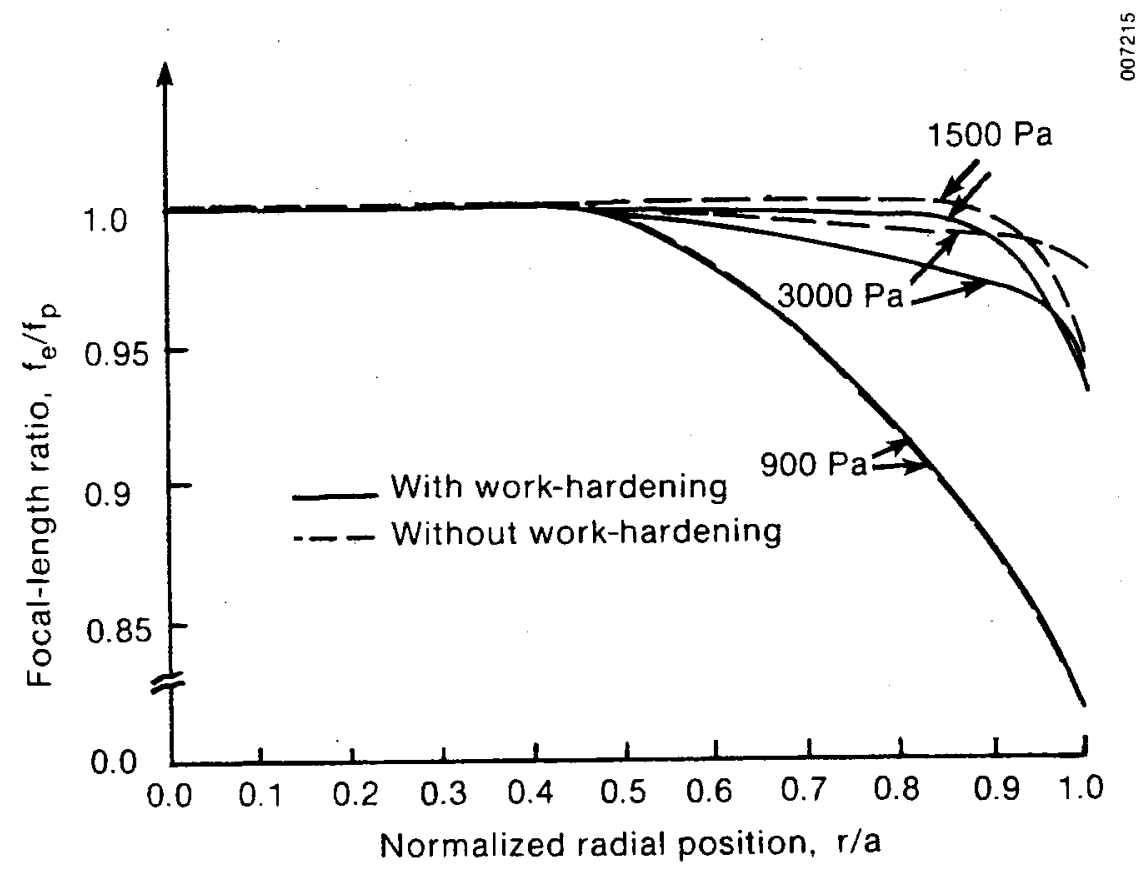

Figure 4-12. Local Normalized Focal Length $\left(f / f_{p}\right)$ as a Function of Normalized Radius for Work-Hardening and Perfectly Plastic Material Response at Several Different Applied Pressures

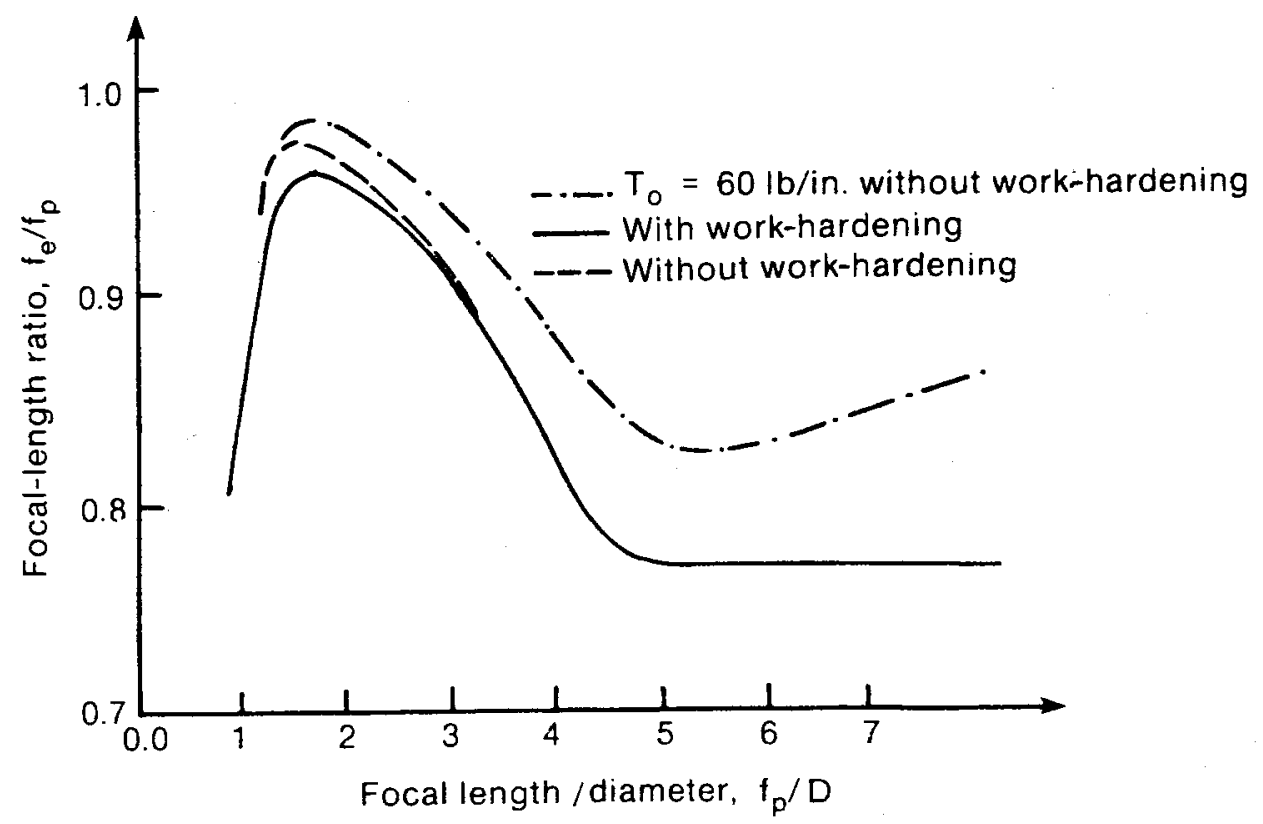

Figure 4-13. Normalized Membrane-Edge Focal Length $\left(f_{e} / f_{p}\right)$ as a Function of $f_{p} / D$
for Both Work-Hardening and Non-Work-Hardering Material Response 
initial tension because the untensioned membrane assumes a very nonspherical shape even for small loads. However, as the membrane deforms and attains smaller $f_{p} / D$ values, the strain increases dramatically and the net average tension increases and improves the contour for the initially untensioned membrane somewhat. Eventually, as the plastic design range is reached, the effects of the initial tension and the corresponding initial elastic strains become negligible compared to the gross plastic effects and the significantly more uniform stress states that now exist.

Before moving on to the next section, note that we carried out analyses corresponding to nominal $f_{p} / D$ levels as low as 0.93 . For large strain conditions, accuracy limitations with the analysis methods restricted the investigation (see Appendix B). This occurs even though significantly smaller $\mathrm{f} / \mathrm{D}$ levels should be attainable in practice, as has been experimentally verified in prior [4,5] and in recent unpublished studies being carried out by DOE.

\subsection{Deformation Response Caused by Subsequent Pressure Reduction}

Up to this point, we have considered only uniformly loaded membranes with monotonically increasing pressure levels. Note that for small $f_{p} / D$ values the required forming pressure is quite high relative to the pressure needed to stabilize the membrane in a wind environment.* Hence the forming pressure may be significantly reduced in actual operations, and the impact of doing so should be investigated.

In Figure 4-14, we illustrate the impact of the unloading effect on membrane focal length by plotting the local normalized focal-length ratio as a function of normalized radial position. The pressure on the membrane was gradually reduced from 3000 to $1000 \mathrm{~Pa}$ for both the work-hardening and the non-work-hardening cases. The most dramatic focal-length variations due to unloading occur in the center and at the edge. Proceeding from the membrane center, the focal length is a minimum at the center, rises rapidly out to a radius of about $1.5 \mathrm{~m}$, and tends to level out over much of the membrane surface until the edge region is reached. We see that the focal-length variation in the membrane center actually increases for decreasing pressure load, thus somewhat decreased optical performance near the center can occur with decreased pressure loading. For instance, at membrane center the $\mathrm{f} / \mathrm{f}$ ratio drops from 0.96 at a pressure of $3000 \mathrm{~Pa}$ to 0.86 at $1000 \mathrm{~Pa}$. This is caused by a significant drop in tension in the membrane center region as the pressure load is decreased, which is in turn caused by the release of elastic strain energy. Further, at the membrane edge region, the focal-length variation initially decreases with lowered pressure loading, and the optical performance might be expected to improve in this region for small pressure drops. For instance, for the work-hardening case considered here, the edge focal length variation decreases with unloading from $3010 \mathrm{~Pa}$ to about $2000 \mathrm{~Pa}$; further decreases in pressure loading cause the edge distortion to increase, resulting in longer focal lengths. Hence, in certain situations the benefit of the unloading effects near the edge may result in an overall opticalperformance improvement because of area considerations. Finally, another effect of unloading is that the nominal focal length $f_{p}$ increases slightly as the applied pressure is lowered. These effects are caused primarily by the overall elastic rebound and reverse yielding processes that accompany the pressure unloading. The unloading process can be quite complex because of the hysteresis associated with the loading/unloading history at

* To put this in perspective, typical survival winds are $90 \mathrm{mph}$ or about $40 \mathrm{~m} / \mathrm{s}$, resulting in a dynamic pressure of about $990 \mathrm{~Pa}$. In a typical drumlike two-membrane design, as shown in Figure 3-1, either membrane will experience about half of this load in the worst possible situation. 


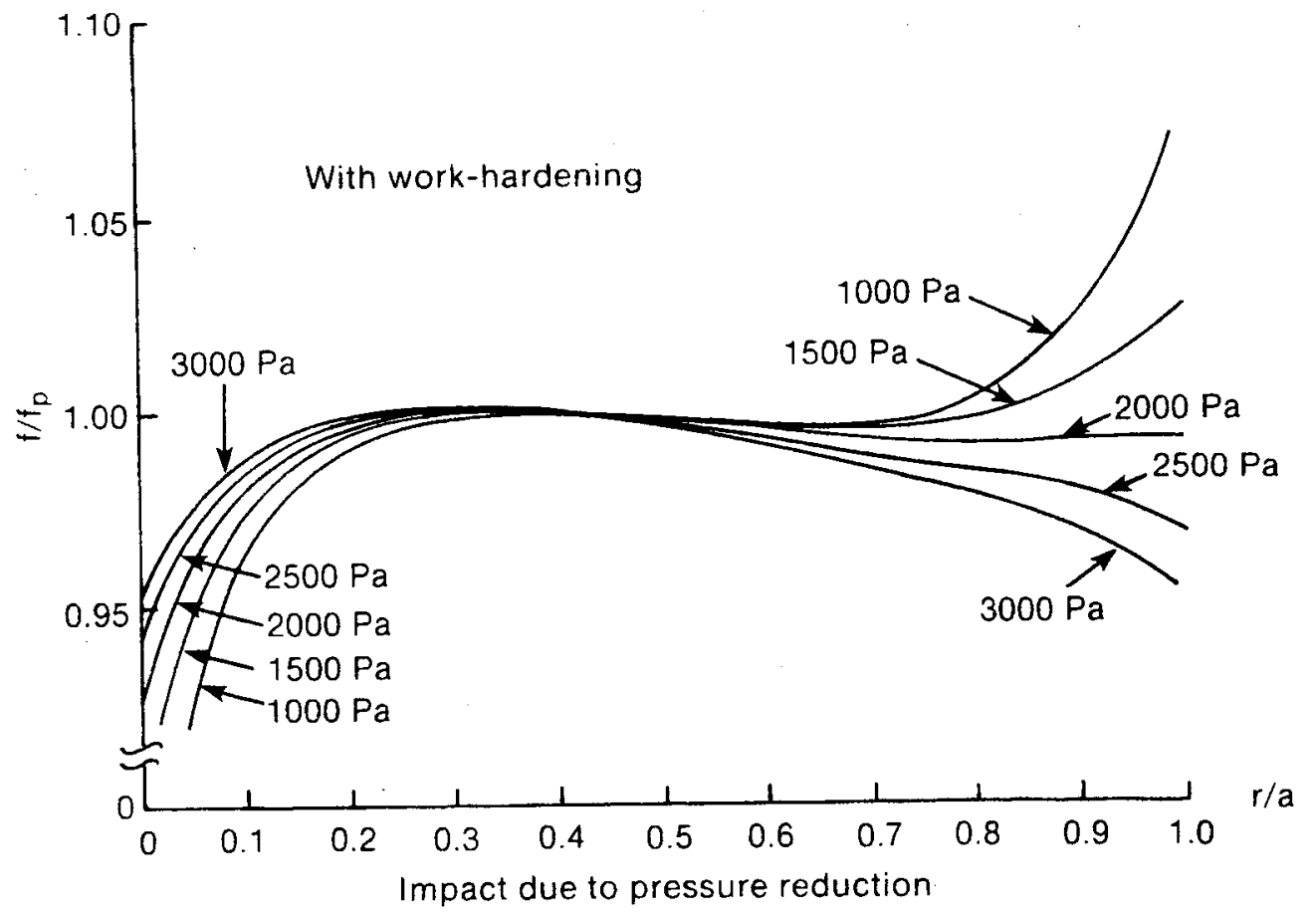

Figure 4-14. Normalized Focal Length $\left(f / f_{p}\right)$ Due to Pressure Reduction as a Function of Normalized Radidl Position for Work-Hardening Material Response and Several Pressure Levels

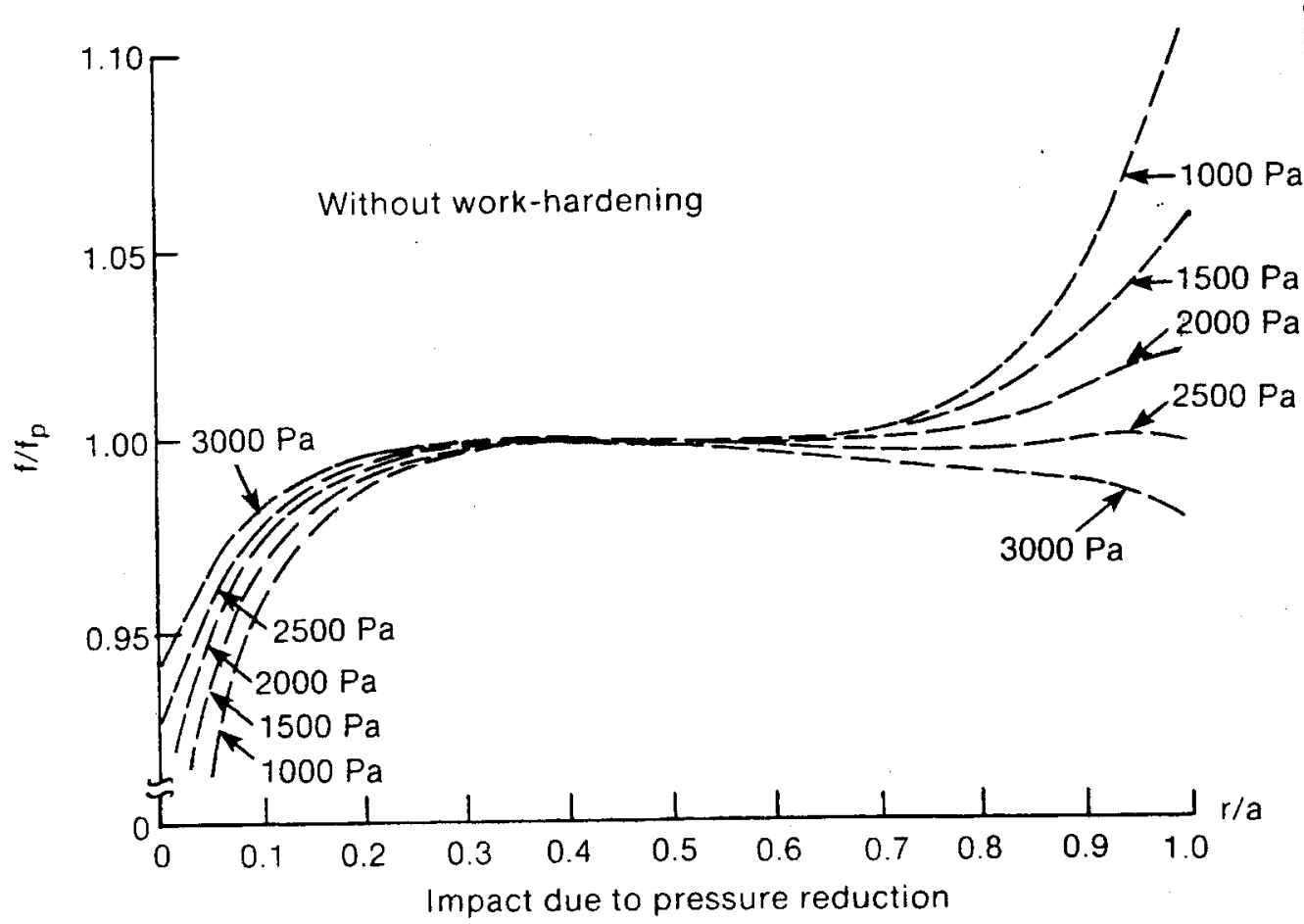

Figure 4-15. Normalized Focal Length ( $/ \mathrm{f}_{\mathrm{f}}$ ) Due to Pressure Reduction as a Function of Normalized Radial Position for Non-Work-Hardening Material Responses and Several Pressure Levels 
each joint in the membrane. An example of this hysteresis is illustrated in Figure 4-3b for the assumed inelastic material responses corresponding to an equivalent uniaxial state of stress.

When considering non-work-hardening or perfectly plastic material response, the loaddeformation response will be similar to that observed in Figure 4-14, as shown in Figure 4-15; however, several differences exist. First, a somewhat flatter response occurs over much of the radial span. Second, the focal-length-ratio variation in the membrane center is not as pronounced as in the work-hardening case. For instance, at the membrane center the $\mathrm{f} / \mathrm{f}_{\mathrm{p}}$ ratio drops from 0.93 at a pressure of $3000 \mathrm{~Pa}$ to about 0.86 at $1000 \mathrm{~Pa}$. Finally, the peak focal length was increasingly found to be near the radial support as the unloading proceeded (we still used the broad flat region in this case to define $f_{p}$ ). 


\subsection{CONCLUSIONS AND RECOMMENDATIONS}

\subsection{Conclusions}

We have studied the shape-distortion effects relative to the desired parabolic reflector shape that is associated with the uniform pressure forming of initially flat, circular membranes supported only at the edges. In addition, we have defined the causes of those distortions and the response mechanisms leading to the final shapes. We have related these surface-distortion effects to variations in focal length over the membrane surface. As such, the aforementioned analyses and results clearly indicate the load and deformation inclined shape effects that will cause degradation of optical performance. More specifically, based on the results obtained and the assumptions defined above, we have reached the following conclusions.

- Significant shape distortions of pressure-loaded, initially flat membranes, relative to the desired parabola, can result from a number of mechanisms, especially in dish applications. The distortions are attributable to nonuniform tension states in the membrane and to spherical aberrations relative to the parabolas. The significant nonuniform tension states can result from either elastic or inelastic material response.

- Pressure-loaded membranes tend to have a spherical shape, which sometimes can closely approximate an ideal parabolic surface. A close approximation for larger $f_{o} / D$ 's is the sphere, but for very small $f_{o} / D$ 's this approximation becomes increasingly poorer. For elastic membranes, the membrane is always flatter in the center region and more sloped near the outer radius than is the perfect sphere, which has the same curvature at the apex. In addition, the spherical shape that is approached with plastic deformation always has more curvature (i.e., lower radius of curvature and shorter focal length) at the outer radius than the nominal perfect sphere does. Thus, it appears that the sphere is the best approximation we might approach with the elastic/ plastic forming of the metal membranes.

- Reasonably good spherical shapes that quite closely approximate the ideal parabolic contours can be attained with totally elastic membrane systems if $f_{0} / D>2.0$ and if $E t / T_{0}$ is small. When $E t / T_{0}$ is large, nonuniform tension states in the membrane can cause unacceptable distortions. Further, if $E t / T_{0}$ is large, the required $f_{o} / D$ for acceptable surface contours may grow appreciably above 2.0 to limit the distortions caused by elastic material response. Further, if $f_{o} / D<2.0$ even when $\cdot E t / T_{0}$ is small, the disagreement between the spherical and parabolic contours may be a concern from an optical perspective.

- For heliostats with typical nominal $\mathrm{f}_{\mathrm{o}} / \mathrm{D}$ values $>12.0$, surface distortions induced by plastic- and elastic-material response may be easily avoided by good design procedures. Further, at these $f_{o} / D$ values, the difference between the corresponding spherical and ideal parabolic shapes is negligible.

- For large-diameter single modules with an $\mathrm{f}_{\mathrm{o}} / \mathrm{D} \leq 2.0$, the use of metals will in general lead to inelastic material response. In fact, for steels, the smallest nominal $\mathrm{f}_{\mathrm{o}} / \mathrm{D}$ (based on average strain arguments) obtainable without plastic material response is about 3.5, whereas for aluminum, the corresponding smallest $f_{o} / D$ is about 2.0 . On the other hand, high-strength polymers with low moduli may be able to attain low $\mathrm{f}_{\mathrm{o}} / \mathrm{D}$ levels $<1.0$ and still remain elastic when pressure loaded; for $\mathrm{f}_{0} / \mathrm{D}$ 's $<1.0$ elastic designs do not appear feasible.

- Elastic-material response can of ten lead to significantly larger deviations from a perfect sphere than plastic-material response. This is illustrated most clearly in Figures 4-12 and 4-13. This is because the plastic deformations will tend to relieve 
some of the stress nonuniformities caused by elastic deformations and will thus make the stress distribution over the membrane surface more uniform; hence the shape of the membrane will become more spherical.

- When under pressure loading, the nonuniformity in membrane focal length always increases monotonically with radius and is increasingly nonlinear near the edge. Inelastic material response in general causes the nonuniformity in focal length to occur at larger radii until $f / D$ values of about 1.5 are reached.

- Work hardening, which was considered here, did not appear to have a large deleterious effect on the surface contour, although for the cases studied here non-work-hardening material response always led to somewhat better focal-length uniformity. The major deleterious impact of work hardening appears to be due to the somewhat greater stress nonuniformity at the edge of the membrane when work hardening is present.

- When considering inelastic material response, a small amount of work hardening can be beneficial since the increased stress can help of fset the decreased membrane thickness in regions of large plastic flow near the membrane center, thus keeping the net membrane tension more nearly constant. Fur thermore, since the maximum strains occur in the center, work hardening can make the flow more stable and lessen the tendency for rupture in the center region.

- A reduction of the forming pressure on a membrane that has undergone large plastic deformations worsens the focal-length nonuniformity in the membrane center region. Initial pressure reductions also result in better focal length uniformity near the edge. Hence it is possible, because of the area effect at large radii, that the overall optical effect may improve somewhat for some pressure reduction levels. An optical analysis is needed to verify this. For large pressure load reductions we observed increased distortions near the edge. These response phenomena that accompany pressure unloading are caused by elastic rebound and material hysteresis.

- Material elastic rebound and hysteresis can have a significant impact on the final optical shape as seen from our focal length predictions. This will be especially true if the operational pressure load on the membrane is significantly lower than the pressure that was used to form the membrane shape.

\subsection{Recommendations for Further Work}

These analyses have addressed only a portion of the structural response issues affecting surface contour. Other issues, which we have not addressed but which can significantly affect the surface contour and the optical quality of the membrane surface, include material property nonuniformities such as anisotropic modulus effects, membrane-thickness nonuniformity, "cabling" effects* attributable to the seams, distortion effects from the frame (on which the membrane is attached) displacements and rotations, and nonuniform pressure loading. Before embarking on a systematic evaluation of these additional effects, it is recommended that we carry out more detailed optical analyses of the shape-distortion effects defined in this work. This will help us ensure that the effects already identified will not prevent this forming approach from being applied to realistic designs. Furthermore, the expense of the kinds of inelastic analyses just completed precludes an extensive study of systems and parameter variations beyond the design approaches that are likely to be considered. Moreover, many of the effects that have not been analyzed, in addition to the deleterious effects that we have identified and

* The so-called cabling problem is caused by the additional material thickness and stiffness in the welded regions of the membranes. 
quantified in this analysis, can possibly be eliminated or at least significantly lessened by using different approaches to surface forming.

Different, potentially attractive forming approaches deserve further consideration as means of effectively forming and attaining highly accurate optical surfaces. For instance, nonuniform but axisymmetric pressure loading might be used to alleviate some of the problems identified in this report. In addition, using a mandrel to form the membrane might be even more helpful. A mandrel could be used for attaining precise predetermined shapes either as a form on which a composite membrane might be laid up or as a forming tool to plastically deform a metal membrane. When used with metal membranes, the mandrel has the potential not only to alleviate greatly the difficulties addressed in this report, but also to significantly reduce cabling effects caused by welds and the effects of anisotropic plastic flow. 


\subsection{REFERENCES}

1. Khoshalm, B. H., "50-kW Solar Membrane Concentrator," presented at the Solar Thermal Collectors Workshop (sponsored jointly by the Saudi Arabian National Center for Science and Technology and the United States Department of Energy), Lakewood, CO, 11-14 April 1983. Published in Khoshalm, B. H., and Williamson, J. S. (eds.), Proceedings of the Fourth SOLERAS Workshop, MRI/SOL--1301, Kansas City, MO: Midwest Research Institute (SOLERAS Project), pp. 20-63. Available from the National Technical Information Service, Springfield, VA 22161.

2. Gehlisch, Klaus, et al., "Large Parabolic Dish Collectors with Small Gas-Turbine, Stirling Engine or Photovoltaic Power Conversion Systems," presented at the 17th Intersociety Energy Conversion Engineering Conference, Los Angeles, CA, 8-13 August 1982, 12 pp.

3. Gehlisch, Klaus, et al., "Small Solar Power Plants with Large Parabolic Dish Collector," presented at the 4th International Solar Forum of the German Solar Energy Society, Berlin, West Germany, 6-9 October 1982, 9 pp.

4. Schlaich, J., and S. Greiner, "Vorgespannte Flächentragwerke aus Metallmembranen," Bauingenieur 53, 1978, pp. 77-87.

5. Mäde, W., and J. Oswald, "Bedeutung der Fliesskurve für dünne Bleche," Fertigungstechnik und Betrieb, June 1966, pp. 354-361.

6. McGlaun, M., "Solar Plant I," Proceedings of the Distributed Receiver Solar Thermal Technology Conference, SAND84-2454, Albuquerque, NM: Sandia National Laboratories, April 1985.

7. Kleinwachter, H. and J., "Economically Working Big Scale Solar Power Stations in Pneumatic Light Weight Construction," Revue Internationale D'Heliotechnique, Comples, 1979, Marseilles, France: Cooperation Mediterraneenne pour l'Energie Solaire, pp. 9-14.

8. Murphy, L. M., "Moderate Axisymmetric Deformations of Optical Membrane Surfaces," Journal of Solar Energy Engineering, Vol. 109, No. 2 (pp. 111-120), May 1987.

9. Murphy, L. M., D. Simms, and D. V. Sallis, Structural Design Considerations for Stretched-Membrane Heliostat Reflector Modules with Stability and Initial Imperfection Considerations, SERI/TR-253-2338, Golden, CO: Solar Energy Research Institute, October 1986.

10. Butler, B. L., et al., "Stressed Membrane Research at SAIC," La Jolla, CA: Science Applications International Corporation, October 1985. Presented at the Central Receiver Solar Thermal Technology Conference, Williamsburg, VA, 1-3 October 1985.

11. White, D. L., "Stressed Membrane Reflector," Dallas, TX: Solar Kinetics, Inc., October 1985. Presented at the Central Receiver Solar Thermal Technology Conference, Williamsburg, VA, 1-3 October 1985.

12. Flugge, W., Stresses in Shells, New York: Springer-Verlag, 1966. 
13. Firt, Vladimir, Statics, Formfinding and Dynamics of Air Supported Membrane Structures, Boston, MA: Martinus Nijhoff Publishers, 1983.

14. Frei, Otto (ed.), Tensile Structures, Cambridge, MA: MIT Press, 1982.

15. Starkey, D. J., "Characterization of Point Focusing Test Bed Concentrators," Parabolic Dish Solar Thermal Power Annual Program Review Proceedings, DOE/JPL1060-46, Pasadena, CA: Jet Propulsion Laboratory, May 1981.

16. Goldberg, V. R., "Test Bed Concentrator," Proceedings of the First Semi-Annual Distributed Receiver Systems Program Review, DOE/JPL-1060-33, Pasadena, CA: Jet Propulsion Laboratory, April 1980.

17. Second Generation Heliostat Evaluation Summary Report, SAND81-8034, Livermore, CA: Sandia National Laboratories, January 1982.

18. Wroton, H. C., "Large Area Glass Metal Heliostats," Morrison, CO: Solar Power Engineering Company, October 1985. Viewgraph presentation at the Central Receiver Annual Meeting, Williamsburg, VA, 2-3 October 1985.

19. Kohnke, P. C., "ANSYS Theoretical Manual," Swanson Analysis Systems, Inc., February 1, 1983, pp. 4.1-4.31.

20. Mendelson, A., Plasticity: Theory and Applications, New York: Macmillan, 1968.

21. Keyser, C. A., Materials Science in Engineering, 3rd edition, Columbus, Ohio: Charles E. Merrill Publishing Company, 1980. Also data sheet for type 303 SM and 303 Se stainless steels supplied by J\&L.

22. Sinharay, G. C., and B. Baner jee, "A New Approach to Large Deflection Analyses of Spherical and Cylindrical Shells," Journal of Applied Mechanics, Vol. 52, December 1985, pp. 872-876. 


\section{SEPI综}




\section{APPENDIX A}

\section{Membrane Focal Length and Curvature Change Corresponding to}

\section{Finite Deformation}

The focal length and local change of curvature for the deformed membrane which was initially flat, can be described by the following procedure. First describe the tangent vector at point $A$ as shown in $F i g . A-1$, in terms of the local radial $(u)$ and normal surface $(w)$ displacements by

$$
\Delta \vec{s}=\Delta \vec{r}+\Delta \vec{v}
$$

where

$$
\Delta \vec{r}=\Delta r \vec{e}_{r}
$$

and

$$
\Delta \vec{v}=\left(\frac{\partial u}{\partial r} \vec{e}_{r}-\frac{\partial w}{\partial r} \vec{e}_{y}\right) \Delta r
$$

Hence

$$
\Delta \vec{s}=\left[\left(1+\frac{\partial u}{\partial r}\right) \vec{e}_{r}-\left(\frac{\partial w}{\partial r}\right) \vec{e}_{y}\right] \Delta r
$$

The slope of the surface at point in Figure $A^{-1}$ which was initially at position $(r, 0)$ is now easily determined in the limit as $\overrightarrow{\Delta s}=0$ by

$$
\tan \xi=\frac{-\left(\frac{\partial w}{\partial r}\right)}{\left(1+\frac{\partial u}{\partial r}\right)},
$$

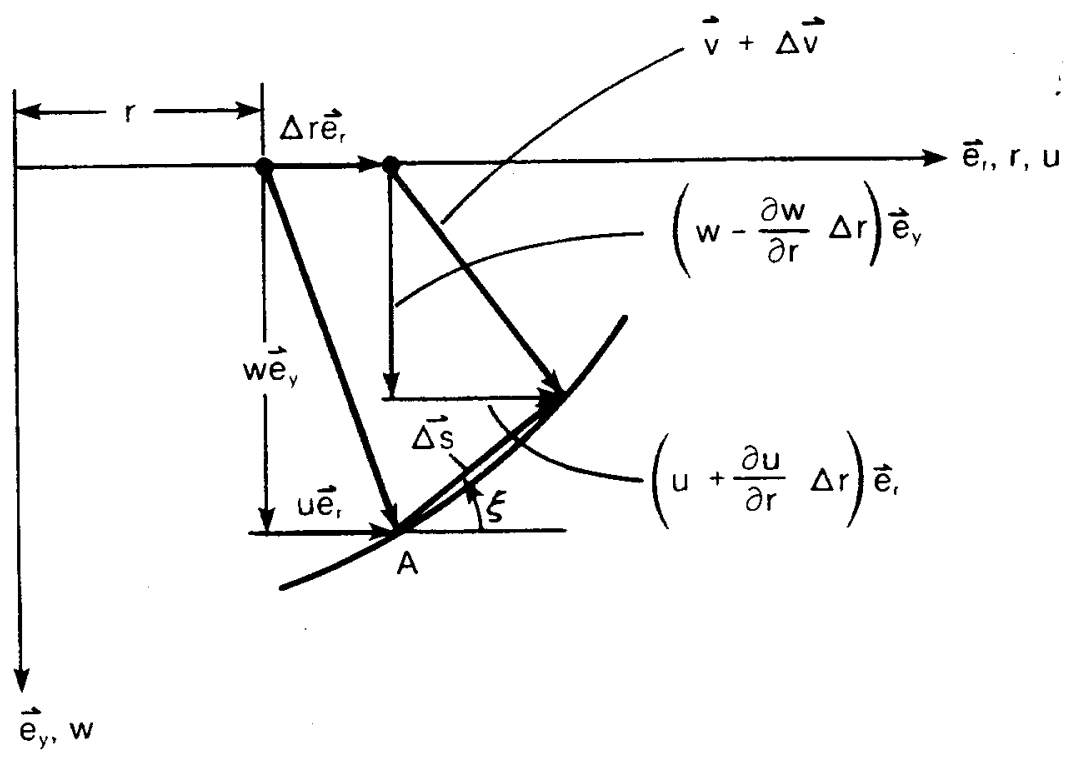

Figure A-1. Nonlinear Geometric Relationship for Membrane Surface 
where $\xi$ is the angle between the tangent vector and the $r$ axis.

The focal length can then be easily determined using Eq. A-5 and the geometric construction shown in Figure A-2. Thus $f$ is seen to be

$$
f=w_{0}-w+(r+u) / \tan \phi
$$

where $w_{0}$ is the center deflation of the membrane which is held fixed at $r=a$ with$$
\tan \phi=2 \tan \xi /\left(1-\tan ^{2} \xi\right)
$$

Since $\phi=2 \xi$.

The local curvature $\left(\frac{1}{R_{\phi}}\right)$ in the meridinal direction can be determined from

$$
\frac{1}{R_{\phi}}=\frac{d \xi}{d s}=\frac{d \xi}{d r} \frac{d r}{d s}
$$

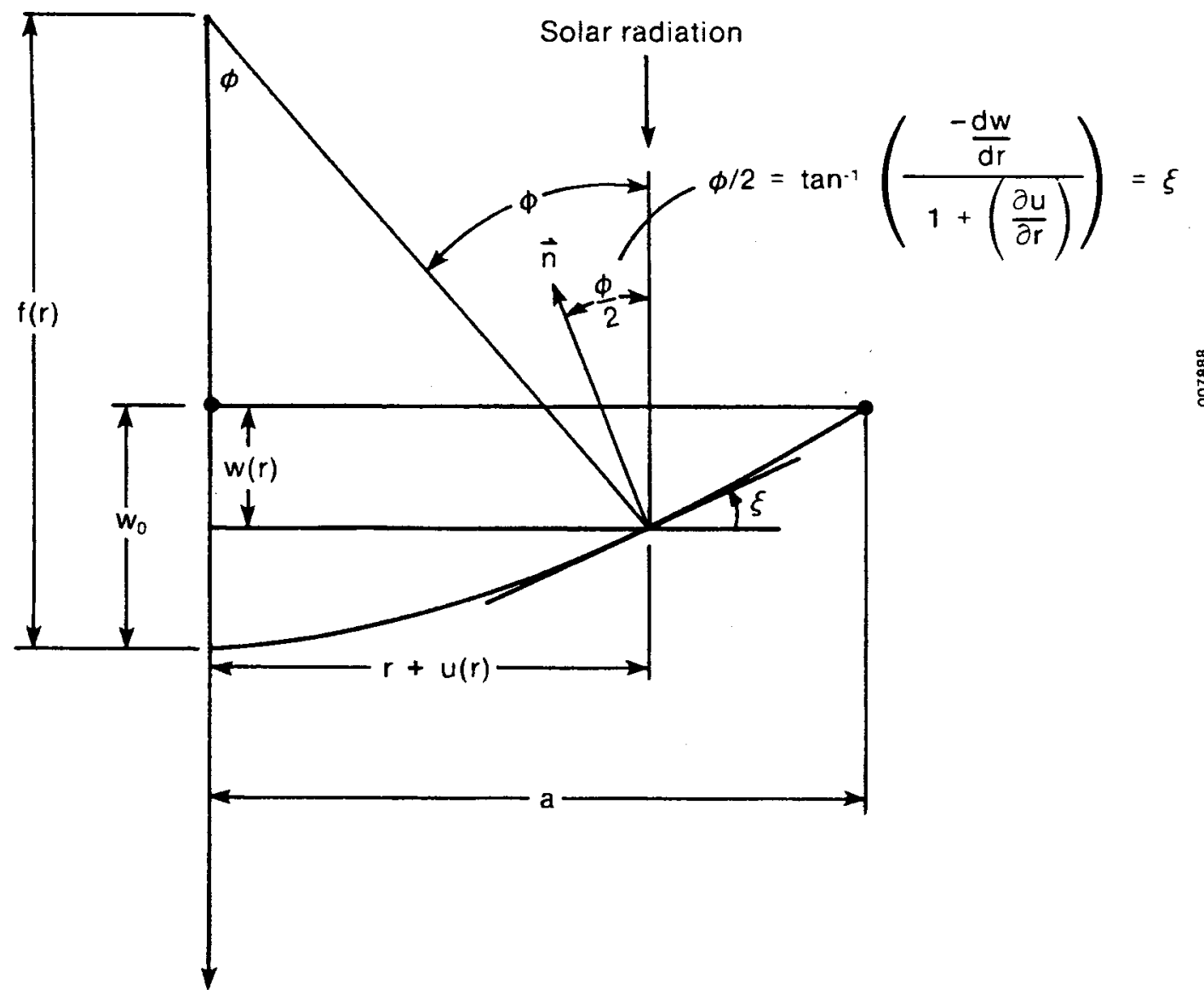

Figure A-2. Geometric and Focal Length Description for Membrane Subject to Large Deformations 
Erom Eq. A-5 it is seen that

$$
\begin{aligned}
\frac{d \xi}{d r} & =\frac{d}{d r} \tan ^{-1}\left(\frac{-\frac{\partial w}{\partial r}}{1+\frac{\partial u}{\partial r}}\right) \\
& =\frac{1}{\left(1+\frac{\partial u}{\partial r}\right)^{2}+\left(\frac{\partial w}{\partial r}\right)^{2}}\left[-\frac{\partial^{2} w}{\partial r^{2}}\left(1+\frac{\partial u}{\partial r}\right)+\frac{\partial w}{\partial r} \frac{\partial^{2} u}{\partial r^{2}}\right] .
\end{aligned}
$$

Further, from Eq. $A-4$, in the 1 imit as $\Delta \vec{s}=0$, it is seen that

$$
\frac{d \vec{s}}{d r}=\left(1+\frac{\partial u}{\partial r}\right) \vec{e}_{r}-\left(\frac{\partial w}{\partial r}\right) \vec{e}_{y}
$$

and hence

$$
\frac{d s}{d r}=\left|\frac{d \vec{s}}{d r}\right|=\left(\left(1+\frac{\partial u}{\partial r}\right)^{2}+\left(\frac{\partial w}{\partial r}\right)^{2}\right)^{\frac{1}{2}} \text {. }
$$

Thus, using Equations $A-8, A-9$, and $A-11$ it is clearly seen that

$$
\frac{1}{R}=\frac{1}{\left[\left(1+\frac{\partial u}{\partial r}\right)^{2}+\left(\frac{\partial w}{\partial r}\right)^{2}\right]^{3 / 2}}\left[-\frac{\partial^{2} w}{\partial r^{2}}\left(1+\frac{\partial u}{\partial r}\right)+\frac{\partial w}{\partial r} \frac{\partial^{2} u}{\partial r^{2}}\right]
$$




\section{APPENDIX B}

\section{Strain Limitations Impacts on Converged Load/Deformation Solutions}

We have not been able to obtain fully converged load/deformation solutions adequate for optical parameter estimations corresponding to $f / D^{\prime} s$ that are significantly less than 1.0. The convergence problem does not appear to be associated with either large deformations or large surface rotations but rather with large strain measures. In particular we found that convergence was increasingly more difficult to insure when equivalent strain in the membrane center exceeded about $3 \%$. We have, however, observed a definite trend in being able to obtain adequate solutions at somewhat lower $f / D$ 's using thicker membranes. We studied this effect for three membranes with thicknesses of $0.254,0.508$, and $0.762 \mathrm{~mm}$, respectively (other geometric and material properties of the stainless steel membrane with work hardening, as described in Table 4-1, were used for this study). In particular, the smallest $f / D$ 's obtained (corresponding to converged solutions) for these three different membrane thicknesses were $1.17,1.03$, and 0.93 , respectively. of course higher pressures are required for thicker membranes to reach specific f/D ratios. Thus, maximum predicted forming pressure for these three cases were 3000,8200 , and $14,700 \mathrm{~Pa}$, respectively. We also investigated the effect of membrane thickness on the relationship between $f / D$ and the equivalent strain in the membrane center."

For elastic membranes the elastic strain-displacement compatibility conditions dictate a specific relationship between the equivalent elastic strain at the membrane center (which is always a maximum in the initially flat membrane) and the $f / D$ ratio of the deformed membrane, regardless of the membrane thickness.f A similar relationship also would appear to hold for membranes with inelastic material response. This is illustrated in Figure $B-1$, where equivalent strain in the membrane center is shown as a function of $f / D$ for the three different membrane thicknesses previously given.

Figure $B-1$ shows that for the cases considered, a given $f / D$ ratio implies a prescribed equivalent strain at the membrane center regardless of the membrane thickness. Further, a disproportionate amount of strain corresponding to material thinning and rupture was not observed in the cases studied. Such a problem, however, may exist at higher strain levels. Finally our analyses indicate that for an $f / D=0.6$, the equivalent strain at the membrane center would be about $8.7 \%$; thus requiring about three times the peak equivalent strain level for which converged solutions have been obtained.

*As in Section 4.0 in the body, $f / D$ corresponds to the nominal peak focal length of the membrane center region.

†See Steele, C. R., "Forming of Thin Shells" Journal of Applied Mechanics, Transactions of the ASME, pp. 884, December 1975. He shows that for a thin shell the equivalent strain in the center can be approximated by:

$$
\varepsilon \simeq a^{2} /\left(2 R^{2}\right) \simeq 1 /\left[32(f / D)^{2}\right]
$$

if $\varepsilon<0.1$. 


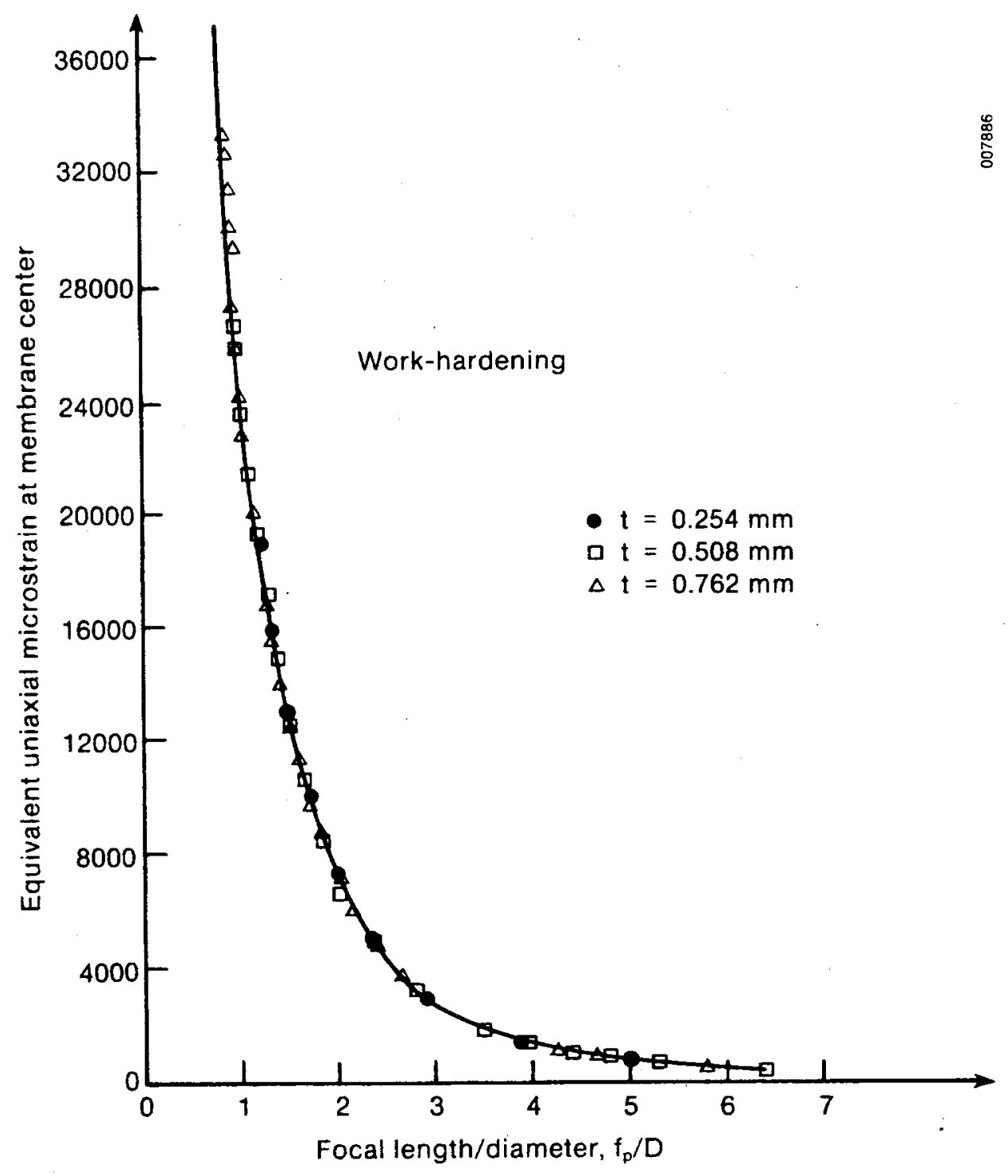

Figure B-1. Equivalent Strain at Membrane Center versus f/d 


\section{SELECTED DISTRIBUTION LIST}

Acurex Solar Corporation

485 Clyde Ave.

Mt. View, CA 94042

Mr. Don Duffy

Advanco Corporation

40701 Monterey Ave.

Palm Desert, CA 92260

Mr. Byron Washom

Arizona Public Service Company

P.O. Box 21666

Phoenix, AZ 85036

Mr. Eric Weber

Battelle Pacific NW Laboratory

P.O. Box 999

Richland, WA 99352

Dr. Ben Johnson

Dr. Kevin Drost

Mr. Tom A. Williams

Bechtel Corporation

P.O. Box 3965

San Francisco, CA 94119

Mr. Pascal deLaquil

Black and Veatch Consulting

Engineers

1500 Meadow Lake Parkway

Kansas City, MO 64114

Dr. Charles Grosskreutz

Brumleve, Mr. Tom

Consultant

1512 N. Gate Road

Walnut Creek, CA 94598

Dan-Ka Products, Inc.

3905 S. Mariposa

Englewood, CO 80110

Mr. Daniel Sallis

Department of Civil Engineering

Colorado State University

Ft. Collins, CO 80523

Dr. Jon Peterka

Professor, Civil Engineering
Department of Civil Engineering

University of Nebraska

60th \& Dodge Street

Omaha, NE 68182-0178

Dr. Chris Tuan

Department of Energy/ALO

P.O. Box 1500

Albuquerque, NM 87115

Mr. Dean Graves

Mr. Nyles Lackey

Department of Energy/HQ

Forrestal Building

1000 Independence Ave., SW

Washington, DC 20585

Dr. H. Coleman

Mr. S. Gronich

Mr. C. Mangold

Mr. M. Scheve

Mr. Frank Wilkins

Department of Energy/SAN

1333 Broadway

Oakland, CA 94536

Mr. Robert Hughey

Mr. William Lambert

Department of Energy/SAO

1617 Cole Boulevard

Golden, CO 80401

Dr. Paul K. Kearns

El Paso Electric

P.O. Box 982

El Paso, TX 79960

Mr. James E. Brown

Electric Power Research Institute

P.O. Box 10412

Palo Alto, CA 94303

Mr. Donald Augenstein

Entech, Incorporated

P.O. Box 612246

DFW Airport, TX 75261

Mr. Walter Hesse 
Georgia Tech Research Institute Georgia Institute of Technology

Atlanta, GA 30332

Dr. Dan O'Neil

Associate Director

Jet Propulsion Laboratory

4800 Oak Grove Drive

Pasadena, CA 91109

Mr. William Owen

LaJet Energy Company

P.O. Box 3599

Abilene, TX 79604

Mr. Monte McGlaun

Luz Engineering Corp.

15720 Ventura Blvd.

Suite 504

Encino, CA 91436

Dr. David Kearney

Martin Marietta

P.O. Box 179

Denver, CO 80201

$\mathrm{Mr}$. Tom Tracey

McDonnell Douglas Astronautics

Company

5301 Bolsa Ave.

Huntington Beach, CA 92647

Mr. Jim Rogan

Meridian Corporation

5113 Leesburg Pike

Suite 700

Falls Church, VA 22041

Mr. Dinesh Kumar

3M Corporation

3M Center Building, 207-1W-08

St. Paul, MN 55101

Mr. David Hill

Mr. Burton A. Benson

NASA Lewis Research Center

21000 Brookpark Road

Cleveland, $\mathrm{OH} 44135$

Dr. Dennis Flood

Mr. Ted Mroz, MS-301-5

Dr. Joe Savino, MS-301-5
NASA-Johnson Space Center

NASA Road One - EPS

Houston, TX 77058

Mr. William Simon

Pacific Gas and Electric Company

3400 Crow Canyon Rd.

San Ramon, CA 94583

Mr. Gerry Braun

Rockwell International

Energy Systems Group

8900 DeSoto Ave.

Canoga Park, CA 91304

$\mathrm{Mr}$. Tom $\mathrm{H}$. Springer

Sandia National Laboratories

Division 8133

Livermore, CA 94550

Mr. A. Skinrood

Sandia National Laboratories

P.O. Box 5800

Albuquerque, NM 87185

Mr. John Otts - 6222

Mr. James Leonard - 6227

Dr. Donald Schuler - 6220

Dr. Tom Mancini - 6227

Dr. Dan Alpert - 6226

Science Applications, Inc.

10401 Roselle Street

San Diego, CA 92121

Dr. Barry Butler

Solar Energy Industries Association

1717 Massachusetts Ave., NW, No. 503

Washington, DC 20036

Mr. Carlo La Porta

Mr. David Goren

Mr. Hal Seilstad

Solar Kinetics, Inc.

P.O. Box 47045

Dallas, TX 75247

Mr. Gus Hutchison

Southern California Edison

P.O. Box 337

Daggett, CA 92323

Mr. Charles Lopez 
University of Arizona

Dept. of Mechanical \& Aerospace

Engineering

Tucson, AZ 85721

Dr. Kumar Ramohalli

Dr. Shiv Joshi

University of Arizona

Dept. of Electrical Engineering

Tucson, AZ 85721

Dr. Roger Jones

DFVLR

German Aerospace

Research Establishment

Linder Höhe

D-5000 Köln 90

West Germany

Ingo Susemihl, Dipl.-Ing.

Solar Energy Research Institute

Mr. B. P. Gupta

Dr. Dave Johnson

Mr. Al Lewandowski

Dr. L. M. Murphy

Mr. Chuck Kutscher 


\begin{tabular}{|c|c|c|c|}
\hline $\begin{array}{l}\text { Document Control } \\
\text { Page }\end{array}$ & $\begin{array}{l}\text { i. SERI Report No. } \\
\text { SERI/TR-253-3025 }\end{array}$ & 2. NTIS Accession No. & 3. Recipient's Accession No. \\
\hline \multirow{3}{*}{\multicolumn{3}{|c|}{$\begin{array}{l}\text { 4. Title and Subtitle } \\
\text { The Formation of Optical Membrane Reflector Surfaces } \\
\text { Using Uniform Pressure Loading }\end{array}$}} & \multirow{2}{*}{$\begin{array}{l}\text { 5. Publication Date } \\
\text { August } 1987 \\
\end{array}$} \\
\hline & & & \\
\hline & & & \\
\hline \multicolumn{3}{|c|}{$\begin{array}{l}\text { 7. Author(s) } \\
\text { L. M. Murphy, C. Tuan }\end{array}$} & \\
\hline \multirow{2}{*}{\multicolumn{3}{|c|}{$\begin{array}{l}\text { 9. Performing Organization Name and Address } \\
\text { Solar Energy Research Institute } \\
\text { A Division of Midwest Research Institute } \\
1617 \text { Cole Boulevard } \\
\text { Golden, CO } 80401\end{array}$}} & $\begin{array}{c}\text { 10. Project/Task/Work Unit No. } \\
5121.32\end{array}$ \\
\hline & & & $\begin{array}{l}\text { 11. Contract (C) or Grant (G) No. } \\
\text { (C) } \\
\text { (G) }\end{array}$ \\
\hline \multirow{2}{*}{\multicolumn{3}{|c|}{ 12. Sponsoring Organization Name and Address }} & $\begin{array}{l}\text { 13. Type of Report \& Period Covered } \\
\text { Technical Report }\end{array}$ \\
\hline & & & 14 \\
\hline \multicolumn{4}{|l|}{ 15. Supplementary Notes } \\
\hline \multicolumn{4}{|c|}{$\begin{array}{l}\text { Potentially high quality optical reflector surfaces are attainable with the use of } \\
\text { pressure formed membranes. Such reflector surfaces offer the prospect of very low } \\
\text { weight and low cost. The formation of such surfaces, using initially flat circular } \\
\text { membranes with uniform pressure loading, is studied in this paper. Finite } \\
\text { axisymmetric deformations, along with both linear and nonlinear material response } \\
\text { is considered. A wide range of focal-length-to-diameter ratios (above } 0.6 \text { ) are } \\
\text { addressed and the structural/optical response mechanisms that lead to optical } \\
\text { distortions relative to ideal parabolic reflector shapes are also considered. } \\
\text { Results show that elastic material response can often lead to a significantly larger } \\
\text { deviation from the ideal shape than will inelastic material response. This results } \\
\text { primarily from the ability to limit stress nonuniformities when inelastic material } \\
\text { response is operative. Furthermore, when under pressure loading the membrane focal } \\
\text { length decreases monotonically with increasing radius for both linear and nonlinear } \\
\text { material response. Further, the predicted focal length variation is increasingly } \\
\text { nonlinear near the membrane support. }\end{array}$} \\
\hline \multirow{2}{*}{\multicolumn{4}{|c|}{$\begin{array}{l}\text { 17. Document Analysis } \\
\text { a. Descriptors } \\
\text { concentrating collectors, optical systems, parabolic dish reflectors, heliostats } \\
\text { b. Identifiers/Open-Ended Terms }\end{array}$}} \\
\hline & & & \\
\hline \multicolumn{3}{|l|}{ 18. Availability Statement } & 19. No. of Pages \\
\hline \multirow{2}{*}{\multicolumn{3}{|c|}{$\begin{array}{l}\text { National Technical Information Service } \\
\text { U.S. Department of Commerce } \\
5285 \text { Port Royal Road } \\
\text { Springfield, Virginia } 22161\end{array}$}} & \\
\hline & & & A04 \\
\hline
\end{tabular}

